\title{
Ardée et les Rutules : réflexions sur l'émergence et le maintien des identités ethniques des populations du Latium pré-romain
} Stéphane Bourdin

\section{Résumé}

Les habitants de la ville latine d'Ardée étaient désignés comme des «Rutules », du nom d'un ancien peuple du Latium, traditionnellement considéré comme apparenté aux Étrusques. En réalité, il s'agit d'une population latine qui choisit de maintenir une identité ethnique distincte. La présente étude analyse les modalités de l'emploi de cette identité dans la tradition annalistique romaine, avant de dégager les différentes phases de la reconstruction idéologique du passé de la ville d'Ardée. On distingue ainsi une tradition argienne, qui vise à rattacher Ardée à l'épos grec, une tradition troyenne (distincte des traditions troyennes de Rome et Lauinium), qui pose Ardée comme la concurrente de Lauinium et une tradition «rutule », visant à légitimer, à travers la revendication d'un rôle panlatin de l'Aphrodisium et à travers la figure du roi Turnus, double de Turnus Herdonius, la volonté d'hégémonie des Ardéates sur la ligue latine à la fin du Vle siècle av. J.-C.

\section{Citer ce document / Cite this document :}

Bourdin Stéphane. Ardée et les Rutules : réflexions sur l'émergence et le maintien des identités ethniques des populations du Latium pré-romain. In: Mélanges de l'Ecole française de Rome. Antiquité, tome 117, n². 2005. Antiquité. pp. 585-631;

https://www.persee.fr/doc/mefr_0223-5102_2005_num_117_2_10116

Fichier pdf généré le 05/04/2018 


\section{ARDÉE ET LES RUTULES \\ RÉFLEXIONS SUR L'ÉMERGENCE ET LE MAINTIEN \\ DES IDENTITÉS ETHNIQUES DES POPULATIONS \\ DU LATIUM PRÉROMAIN *}

La cité d'Ardée, à $37 \mathrm{~km}$ de Rome, incarnait pour les Anciens le type même de la ville déchue. Virgile rappelait ainsi qu'à son époque cette orgueilleuse cité n'était plus qu'un nom ${ }^{1}$. Les recherches archéologiques confirment cette ancienne splendeur et on connaît entre autres l'imposant système de fortifications et trois temples d'époque archaïque, décorés de terres cuites architectoniques. Bien qu'appartenant géographiquement au Latium, les habitants d'Ardée sont traditionnellement qualifiés, dans les sources littéraires, de «Rutules» et distingués de ce fait des «Latins» proprement dits ${ }^{2}$. On s'est penché par le passé sur le problème de l'origine des Rutules, en qui l'on a voulu voir, tour à tour, des populations de substrat

* Je tiens à remercier ici M. le Professeur Dominique Briquel et M. Julien Dubouloz pour l'intérêt porté à ce travail, pour leurs précieuses remarques et les suggestions.

${ }^{1}$ Cf. En., VII, 411-413 : Locus Ardea quondam / dictus auis, et nunc magnum manet Ardea nomen, / sed fortuna fuit. (trad. Collection des Universités de France [CUF] : «Les ancêtres la nommèrent jadis Ardée, et aujourd'hui ce grand nom lui demeure. Mais sa splendeur a passé.»). Cette vision s'est maintenue presque jusqu'à nos jours, comme l'atteste encore la description romantique que donnait d'Ardée B. Tilly en 1945 : «Poor ramshackle houses and hovels, roads worn deep into the rock, all speak of the desolation of this most poetic place, honoured in myth, legend and history, now peopled by only some two hundred poor peasants, a mere wraith of what it once was.» (cf. B. Tilly, Vergilian cities of the Roman campagna, dans Antiquity, XIX, 74, 1945, p. 129). Actuellement, la ville d'Ardée connaît une expansion constante, au détriment d'une partie des vestiges archéologiques, et rien n'évoque plus la vision virgilienne.

${ }^{2}$ Sur l'évolution du concept de «Latium», cf. en dernier lieu H. Solin, Sul concetto di Lazio nell'Antichità, dans H. Solin (dir.), Studi storico-epigrafici sul Lazio antico, Rome, 1996 (Acta Instituti romani finlandiae, XV), p. 1-22. 
pré-indoeuropéen, des Étrusques, des Latins etc. Nous chercherons plutôt ici à sortir d'un débat qui ne s'appuie que sur une documentation limitée et contestable, trop souvent tirée à hue et à dia pour les besoins de la démonstration, et nous nous occuperons plutôt des conditions dans lesquelles une telle identité ethnique a pu apparaître et se maintenir, jusqu'à devenir un des pivots du cadre ethnographique italien dans l'Énéide de Virgile.

Les sources littéraires mentionnent les Rutules comme un peuple du Latium, distinct des Latins, comme Pline l'Ancien qui les situe, dans la succession chronologique des populations de la plaine latiale, entre les Aurunces et les Volsques (III, 56) ${ }^{3}$. On en retient l'idée d'une pluralité de populations à l'intérieur du Latium, certains peuples renvoyant à l'époque légendaire (Pélasges, Sicules), d'autres à la période historique (Volsques, Aurunces), avant la domination romaine; les Rutules sont au confluent de ces deux ensembles. De même, pour Strabon, les Rutules sont une des populations de l'antique Latium, au même titre que les Èques, les Volsques, les Herniques et les Aborigènes $(\mathrm{V}, 3,2)$. Ils forment donc un groupe ethnique distinct, ce que confirment les termes de gens (Liv., I, 57) ou genus (Liv., XXI, 7), qui leur sont appliqués ${ }^{4}$. Ardée, de son côté, est considérée comme un populus de cette gens des Rutules (Liv., III, 71). Tite-Live indique ainsi clairement qu'Ardée est le centre principal des Rutules (I, 57) : "Ardée était alors aux Rutules, nation puissamment riche pour le pays et pour l'époque.... ${ }^{5}$ et Denys donne également l'impression que les Rutules sont un peuple et que les Ardéates ne sont qu'une communauté appartenant à ce peuple, suivant en cela l'emboîtement logique que respectent systématiquement les auteurs antiques quand ils décrivent l'Italie préromaine ${ }^{6}$. Il évoque les $\pi$ ó $\lambda \varepsilon 1 \zeta$ des Rutules (I, 64, 4), laissant entendre qu'il en existait d'autres outre Ardée ${ }^{7}$. Un peu plus loin, à propos de la révolte des

${ }^{3}$ Cf. Plin., HN, III, 56 : Latium antiquum a Tiberi Cerceios seruatum est m.p.L longitudine: tam tenues primordio imperii fuere radices. Colonis saepe mutatis tenuere alii aliis temporibus, Aborigines, Pelasgi, Arcades, Siculi, Aurunci, Rutuli et ultra Cerceios Volsci, Osci, Ausones, unde nomen Latii processit ad Liri amnem.

${ }^{4} \mathrm{La}$ Souda emploie le terme d' $\ddot{\theta} \theta \mathrm{vos}$, mais pour qualifier les Ardéates eux-

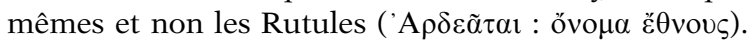

${ }^{5}$ Liv., I, 57 : Ardeam Rutuli habebant, gens, ut in ea regione atque in ea aetate, diuitiis praepollens...

${ }^{6} \mathrm{Cf} . \mathrm{S}$. Bourdin, Les ligues ethniques en Italie: l'exemple des Èques et des Volsques (Ve-IVe s. av. J.-C.), dans Actes du colloque Guerre et diplomatie romaines (IVe-III siècles). Aix-en-Provence, 20-22 janvier 2005, s. p.

${ }^{7}$ Cette notice fait référence à la guerre entre Énée et Turnus et n'a pas réellement de valeur historique. Elle traduit cependant la conception rigide du cadre eth- 
Latins contre Rome en 498, il mentionne les Ardéates dans la liste des cités latines rebelles $(\mathrm{V}, 61,3)$, tout en citant par la suite les Rutules parmi les populations auxquelles les Latins envoient des ambassadeurs pour les soulever contre Rome (V, 62, 3). Denys semble distinguer clairement les deux notions ${ }^{8}$.

Mais il s'agit ici de mentions peu précises et nous sommes bien en peine de trouver dans la tradition antique un autre centre qu'Ardée à attribuer aux Rutules. Nous rencontrons donc un cas où un ethnonyme est utilisé comme "ethnique civique ${ }^{9}$. Ainsi, dans un fragment des Origines de Caton rapporté par Priscien (II, 28 Chassignet ap. Prisc., Gramm., IV, p. $129 \mathrm{H}$ et VII, p. $337 \mathrm{H}$ ), nous avons la liste des populi qui mettent sur pied, probablement vers 500 av. J.-C., une ligue latine opposée à Rome, autour du sanctuaire de Diane à $\mathrm{Nemi}^{10}$; le fragment se clôt sur la mention du populus Ardeatis Rutulus. Dans d'autres cas, nous rencontrons une utilisation de Rutulus seul comme ethnique d'Ardée (Liv., IV, 11), avant que l'ethnique Ardeates seul ne s'impose (Liv., III, 71; IV, 7; 10; V, 43 etc.). Le cas d'Ardée, avec un ethnique double dont un membre diffère du topo-

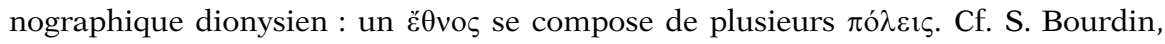
L'ethnographie de l'Italie du IVe siècle avant J.-C. d'après Denys d'Halicarnasse (livres $X I I$ à $X X$ ), dans S. Pittia (éd.), "Denys d'Halicarnasse, historien de l'Italie. Étude des fragments des livres XIV-XX. Table ronde d'Aix-en-Provence, 28 avril 1999», Pallas, 53, 2000, p. 205-239.

${ }^{8}$ On pourrait évidemment objecter que la liste des cités rebelles fournie par Denys est depuis longtemps sujette à caution. Denys mentionne 29 cités, pour bien

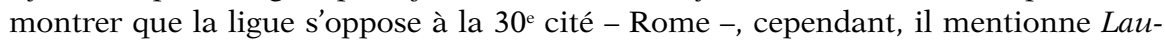
rentum et Lauinium comme deux centres distincts. Il intercale en outre Lanuuium entre les deux. Cf. E. Tais, Un'ipotesi sul Lazio arcaico. Plinio Nat. Hist. III, 69-Dion. Hal. V, 61, 3, dans RCCM, XXVI, 3, 1984, p. 3-22.

${ }^{9}$ Parmi les adjectifs ethniques, nous pouvons en effet distinguer ceux qui correspondent à des peuples ( $\ddot{\theta} \theta \mathrm{vo}$, nomen, gens) et ceux qui correspondent à des unités politiques ( $\pi$ ó $\lambda \mathrm{s}$, populus, ciuitas). Cf. M. H. Hansen, City-ethnics as evidence for polis identity, dans M. H. Hansen et K. Raaflaub (dir.), More studies in the Ancient Greek Polis, Stuttgart, 1996 (Papers from the Copenhaguen Polis Centre, 3), p. 169-196. En règle générale, l'ethnique "civique» dérive du toponyme qui désigne la cité qui en est le centre principal (Roma $>$ Romani, Tusculum > Tusculani), par l'ajout d'un suffixe (-anus, -as en latin, -ite, - ate en étrusque etc.). Cf. E. Seyfried, Die Ethnika des alten Italiens, Zürich, 1951 et J. Perret, Problèmes topographiques au royaume de Latinus (Enéide VII-XII), dans R. Chevallier (dir.), Littérature gréco-romaine et géographie historique. Mélanges offerts à Roger Dion, Paris, 1974 (Caesarodunum, IX bis), p. 177 sq.

${ }^{10}$ Sur ce passage de Caton et son interprétation, on se reportera principalement à C. Ampolo, Ricerche sulla lega latina. II. La dedica di Egerius Baebius (Cato fr. 58 Peter), dans PP, CCXII, 1983, p. 321-326. Cf. infra. 
nyme, n'est pas isolé. Nous le rencontrons également à Lauinium, qui est évoqué comme populus Laurens dans la liste de Caton, tandis que les inscriptions d'époque impériale parlent plutôt des Lauinates Laurentes ${ }^{11}$, mais également à Falerii, dont l'ethnique Falisci, semble être aussi un nom de peuple utilisé comme ethnique civique ${ }^{12}$. Il semble donc que certains noms de peuples, probablement très anciens, aient pu se maintenir en désignant des communautés urbaines, alors que d'autres noms ont continué à désigner des réalités ethniques (Etrusci, Latini, Volsci etc.) ${ }^{13}$. La ville d'Ardée

${ }^{11}$ Dans les inscriptions latines, les Lauinates et les Laurentes sont considérés comme un tout et nous avons ainsi la mention d'un sacerdos Laurentium Lauinatium (CIL, III, 1180; 1509; V, 6357; VI, 2176; 2197; 32.267; VIII, 1439; X, 483; 4271; 7580; XIV, 154 etc.) ou sacerdos Laurens Lauinas (CIL, V, 6357; IX, 4686), sacerdos aput Laurentes Lauinates (ILS, 2748), sacerdos Lauinatium Laurentium (AE 1934, 27), sacerdos et pontifex Laurentium Lauinatium (CIL, VIII, 9368). Laurens Lauinas peutêtre abrégé L.L. (CIL, III, 1456; V, 2044; 2071 etc.). On a aussi des mentions d'un flamen lucularis Laurentium Lauinatium (CIL, XI, 5215), du pontifex Laurentium Lauinatium (CIL, VI, 1531; 1635; X, 797; XI, 3940), en alternance avec le pontifex Laurentinorum (CIL, XII, 408), d'un salius Laurentium Lauinatium (CIL, XIV, 390). Le même ethnique double revient pour les magistratures, avec le praetor Laurentium Lauinatium (CIL, XIV, 172) ou praetor et pontifex Laurentium Lauinatium (CIL, XI, 7555), et pour les institutions, comme l'ordo Laurentium Lauinatium (EE, IX, 592), dénomination alternative du senatus Laurens (CIL, XIV, 2070; 2071). La forme Laurolauinium, que l'on retrouve chez Servius (En., I, 3; III, 390; VII, 59), n'est qu'une reconstruction artificielle des scholiastes tardifs. Cf. A. Grandazzi, Virgile et le Latium archaïque, dans $B A G B, 1979,3$, p. 301-311 et N. Horsfall, s.u. Laurentes, dans Enciclopedia Virgiliana, III, Rome, 1987, p. 141-144. Sur l'indivisibilité de Lauinium et des Laurentes et sur l'inexistence d'un centre de *Laurentum en tant que tel, les remarques de J. Carcopino (Virgile et les origines d'Ostie, Paris, 1919 [Bibliothèque des Écoles françaises d'Athènes et de Rome, 116], p. 171 sq.) n'ont rien perdu de leur valeur.

${ }^{12}$ Plutarque (Cam., 10, 1 et 8) est le seul auteur à fournir un ethnique différent pour distinguer l'ž $\theta$ vo $(\mathrm{V}, 2,9)$ a des difficultés à mettre en relation les deux termes, puisqu'il considère $\Phi \alpha$ -

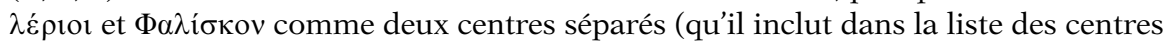
étrusques de la mésogée). Stéphane de Byzance signale, lui, deux centres $\Phi \alpha \lambda \varepsilon \dot{\rho} \rho ı v$

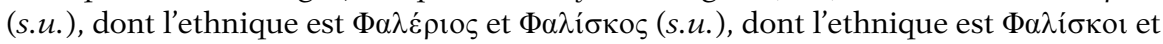
qui serait une fondation argienne. Il semble clair cependant que le toponyme $\Phi \alpha \lambda i ́ \sigma-$

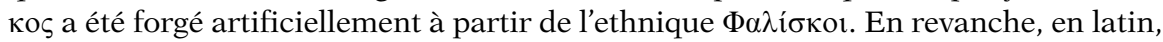
Falisci est utilisé comme ethnique général et pour désigner plus particulièrement les habitants de la cité de Falerii (Liv., V, 27). D'un point de vue linguistique, les deux formes sont clairement distinctes et on peut supposer que le nom du peuple s'est réduit (en latin) au sens de l'ethnique civique (cf. G. Giacomelli, Il falisco, dans A. L. Prosdocimi [dir.], Popoli e civiltà dell'Italia antica. VI. Lingue e dialetti, Rome, 1978, p. 509).

${ }^{13}$ Cf. A. Alföldi, Early Rome and the Latins, Ann Arbor, 1965, p. 14-15. 
se développe à partir du VIII ${ }^{\mathrm{e}} \mathrm{s}$. sur le territoire d'une population de Rutuli et cet ethnique finit par se réduire pour ne plus désigner que les habitants de la cité elle-même, et devenir synonyme d'Ardeates. Nous entrevoyons certes le mécanisme, mais il nous reste cependant à expliquer les raisons du maintien de cette double désignation.

\section{Les Rutules, Population de SubSTRAT ou IDENTIté RÉSIDUELle?}

Les spéculations sur l'origine et sur l'identité ethnique des Rutules ont pour point de départ l'analyse des quelques témoignages linguistiques conservés, essentiellement à travers les toponymes et les ethniques. Pour le toponyme Ardea, les Anciens notaient déjà l'homonymie avec le terme latin désignant le héron, ardea, ce qui occasionnait divers jeux de mots, voire des reconstructions étymologiques. Toutes ces étymologies sont reprises dans le commentaire de Servius (En., VII, 412; G., I, 364) ${ }^{14}$, qui distingue plusieurs explications : Ardea ressemble à ardua, parce que la ville est perchée, mais Servius rappelle qu'Hygin proposait une étymologie fondée sur ardea, oiseau augural. Cette étymologie populaire est à l'origine du récit que l'on retrouve dans les Métamorphoses d'Ovide (XIV, 566 sq.) : au moment de la mort de Turnus, on vit un oiseau s'élever de la ville en flammes, rejetant la cendre au moyen de ses ailes. Le texte d'Ovide joue ici à plusieurs niveaux, en rapprochant aussi bien Ardea d'ardea que d'ardere. Lucain $(\mathrm{V}, 554)$ fait en revanche le lien entre le héron et l'idée de hauteur (arduus), puisque, malgré ses plumes courtes, l'oiseau ose voler en altitude. De même, Virgile (En., VII, 408 sq.) fait précéder l'évocation du nom de la ville par une description du vol d'Allecto aux ailes sombres. Dans tous les cas, il s'agit plus de jeux de mots et d'associations d'idées que d'étymologies réelles. Pour les Modernes, en revanche, le toponyme Ardea appartient probablement au substrat pré-indœuropéen et il est rapproché d'autres toponymes comme Artena, connu chez les Étrusques et chez les Volsques ${ }^{15}$.

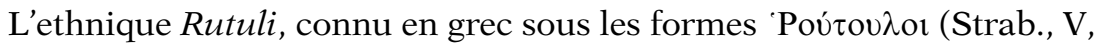

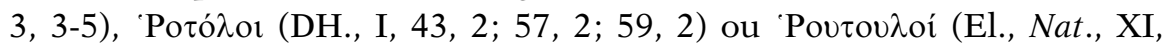
$16)^{16}$, n'a pas donné lieu à autant de spéculations étymologiques. Seul Festus (P. Fest., p. 317 L) se risque a proposer un rapprochement avec le mot Rufuli, en indiquant qu'on désignait par ce terme les tribuns militaires qui

${ }^{14} \mathrm{Cf}$. également Isidore de Séville (XII, 7, 21).

${ }^{15}$ Cf. C. Battisti, Sostrati e parastrati nell'Italia preistorica, Florence, 1959, p. 146.

${ }^{16}$ Cf. G. Vanotti, s.u. Rutuli, dans Der Neue Pauly. Enzyklopädie der Antike, 10, Stuttgart, 2001, p. 1174. 
avaient été nommés par les consuls et non par le peuple. Il précise que leurs attributions avaient été fixées par une loi proposée par un Rutilius Rufus, d'où l'appellation de Rufuli, dérivant vraisemblablement du cognomen, changée ensuite en Rutuli, dérivant vraisemblablement du gentilice. Cette notice ne trouve aucun écho dans la tradition annalistique, mais elle a le mérite de mettre en relation l'ethnique Rutulus avec le gentilice latin Rutilius (et avec le cognomen Rutilus / Rutulus).

Les linguistes ont proposé plusieurs solutions au problème ${ }^{17}$. Pour W. Schulze, les Rutules sont d'origine étrusque ${ }^{18}$. B. G. Niebuhr avait déjà rapproché le nom de Turnus, roi des Rutules, de l'ethnique $T u(r) s c i$, et on a également voulu y voir un lien avec le mot étrusque turns $(E T \text { Vs. 1.170 })^{19}$. Turnus serait un nom désignant «l'Étrusque» et parallèle à des noms étrusques comme Latine ${ }^{20}$. D'ailleurs, Denys d'Halicarnasse désigne Turnus sous la forme Tyrrhénos, «l'Étrusque»(DH., I, 64, 2), tandis qu'une notice de Landulphe Sagax (Historia miscella, I, 2) fait de Daunus, père de Turnus, un roi des Étrusques ${ }^{21}$. Il est toutefois hasardeux de déduire l'identité ethnique d'une population du seul nom d'un de ses monarques, qui de surcroît n'apparaît pas en dehors de la geste d'Énée ${ }^{22}$. Les

${ }^{17}$ Pour une présentation synthétique de toutes les hypothèses émises, cf. H. Philipp, s.u. Rutuli, dans RE, I, A, 1, 1914, col. 1282-1283.

${ }^{18}$ Cf. W. Schulze, Zur Geschichte lateinischer Eigennamen, Berlin, 1904, p. 581.

${ }^{19}$ On a parfois supposé que Turns était une forme adjectivale signifiant "(fils) de Vénus» (cf. W. Bradenstein et H. Philipp, s.u. Turnus, dans RE, VII, A, 2, 1943, col. 1409-1413), mais ce rapprochement est rejeté par C. De Simone (La posizione linguistica della Daunia, dans La civiltà dei Dauni nel quadro del mondo italico. Atti del XIII Convegno di Studi etruschi e italici. Manfredonia 21-27 giugno 1980, Florence, 1984, p. 117). Il s'agit plus vraisemblablement du génitif de Turan, dont la forme normale est plutôt Turuns (ET Ta $4.1 ; 4.4 ; 4.5 ; 4-6 ; 4.7 ; 4.8)$.

${ }^{20} \mathrm{Cf}$. J. Heurgon, Recherches sur la fibule d'or inscrite de Chiusi : la plus ancienne mention épigraphique du nom des Étrusques, dans MEFR, 83, 1971, p. 9-28 = Scripta varia, Bruxelles, 1986 (coll. Latomus, 191), p. 257-271.

${ }^{21}$ Cf. C. Ampolo, s.u. Rutuli (Rutuli), dans Enciclopedia Virgiliana, IV, Rome, 1988, p. 619-620.

${ }^{22}$ Cf. A. Traina, s.u. Turno (Turnus), dans Enciclopedia Virgiliana, V, Rome, 1990, p. 324-336. Les tentatives pour voir dans Turnus une divinité indigène, en association avec sa parèdre Juturne, sont peu convaincantes. On ne peut que remarquer l'inconsistance du personnage de Turnus, qui nous apparaît avant tout dans la tradition comme l'anti-Énée, et dont le personnage, chez Virgile, est composé alternativement de traits empruntés aussi bien à Hector qu'à Achille. Cf. P. Schenk, Die Gestalt des Turnus in Vergils Aeneis, Königstein, 1984. Le nom Turnus apparaît par la suite dans la tradition annalistique, porté par des Latins, comme Turnus Herdonius, le chef de l'opposition latine à Tarquin le Superbe (DH., IV, 46-47). L'auteur de 
tenants d'une origine étrusque s'appuient principalement sur un passage d'Appien (R., I, 1, 1), qui qualifie les Rutules de «Tyrrhéniens». Néanmoins, il faut probablement entendre ici «tyrrhénien» dans son acception large, comme "populations du versant tyrrhénien de l'Italie» ${ }^{23}$; en outre, ce passage provient de la Bibliothèque de Photius (p. 16 b 4 Bekk.) et il n'est pas exclu que la précision sur l'identité ethnique des Rutules soit due à Photius, désireux de rendre intelligible son résumé. Il s'agirait alors d'une glose imprécise et non du texte d'Appien lui-même ${ }^{24}$.

F. Ribezzo, de son côté, rapproche leur nom du lat. ruber. Ils seraient donc d'origine indo-européenne et appartiendraient au vieux fonds «ausonien» de la population du Latium ${ }^{25}$. G. Devoto y voit en revanche une population appartenant au substrat pré-indoeuropéen, comme les Ligures et les Étrusques, ce qui expliquerait les rapprochements phonétiques et toponymiques que l'on peut établir et ce qui les apparenterait, au point de vue linguistique au moins, aux Étrusques ${ }^{26}$. Enfin, C. Battisti se contente de rappeler tous ces points de vue, sans trancher entre eux; il signale cependant le rapprochement avec les toponymes apuliens Rudiae et $R u b i$, euxmêmes en relation avec ruber et renvoyant à l'i.e. *reudho-s ${ }^{27}$, auquel s'ajouterait le suffixe -uli, comme dans d'autres ethniques (Apuli, Poediculi). Les Rutules seraient donc les «rouges»/ «blonds», ou les «habitants des terres rouges ${ }^{28}$.

l'OGR (XIII, 4) fait même une confusion en appelant «Turnus Herdonius» le roi des Rutules. Cf. infra.

${ }^{23}$ Sur cet emploi au sens géographique et non ethnique du terme "tyrrhénien», cf. D. Briquel, Les Pélasges en Italie. Recherches sur l'histoire de la légende, Rome, 1984 (Bibliothèque des Écoles françaises d'Athènes et de Rome, 252), p. 572 et D. Musti, L'immagine degli Etruschi nella storiografia antica, dans Secondo Congresso internazionale etrusco. Firenze 26 Maggio-2 Giugno 1985. Atti, I, Rome, 1989, p. 30.

${ }^{24} \mathrm{Ce}$ phénomène a été bien mis en lumière par $\mathrm{S}$. Pittia lors d'un récent colloque à Aix-en-Provence. Cf. S. Pittia, La fiabilité historique des fragments d'Appien sur l'histoire diplomatique et militaire de Rome aux $I V^{e}-I I I^{e}$ siècles, dans Guerre et diplomatie romaines....cit. n. 6 , s. p.

${ }^{25} \mathrm{Cf}$. F. Ribezzo, Unità italica ed unità italo-celtica. Del rapporto originario e storico tra Laziali-ausonici e Umbro-sabellici, dans RIGI, XVI, 1932, p. 28-29.

${ }^{26}$ Cf. H. Philipp, art. cit. n. 17. La survivance de toponymes «étruscoïdes», comme Tusculum ou Artena, dans le Latium, s'explique peut-être davantage par le maintien de noms pré-indœuropéens que par une invasion étrusque du Latium à l'époque des Tarquins. Sur la nature de la présence étrusque dans le Latium archaïque, cf. A. Naso, Gli Etruschi nel Lazio antico, dans G. Camporeale (dir.), Gli Etruschi fuori d'Etruria, San Giovanni Lupatoto, 2001, p. 220-235.

${ }^{27}$ Cf. D. Briquel, op. cit. n. 15, p. 149 et 53. Ceci dit, à partir d'une telle racine, on attendrait plutôt un [f] (Rufus) ou un [b] (ruber) qu'un [t].

${ }^{28}$ Cf. G. Devoto, Protolatini e Tirreni, dans SE, XVI, 1942, p. 416. 
D. Briquel, qui a étudié les traditions relatives à la présence ancienne de Dauniens dans le Latium, parvient aux mêmes conclusions ${ }^{29}$. Ces «Dauniens», que l'on retrouve encore sous la forme $\Delta$ avvítal chez le pseudoScylax (§ 15) et dans l'Alexandra de Lycophron (v. 1253-1254), correspondent à une ancienne extension des populations italiques, commune aux deux versants de la péninsule. Ils sont mis en relation avec les Rutules, notamment à travers la tradition qui nomme Daunus le père de Turnus (Virg., En., X, 616; 688; XII, 22; 90; 934; Sil., VIII, 357) ${ }^{30}$ et qui fait donc des Rutules une gens Daunia (Virg., En., VIII, 146) et dans un passage de Vibius Sequester qui met clairement en parallèle les deux populations (VII, 37). En outre, la tradition sur le uer sacrum des Sacrani, que Servius fait partir d'Ardée (En., VII, 796) ${ }^{31}$, tend à rattacher également les Rutules au vieux fond italique de la population du Latium ${ }^{32}$.

Du reste, à l'exception du fragment d'Appien conservé par Photius, la tradition littéraire insiste plutôt sur la parenté entre les Latins et les Rutules. Ainsi, Virgile qualifie les Rutules de consanguinei des Latins (En., XII, 40). De son côté, Silius Italicus, à propos de la colonisation de Sagonte, écrit que la migration de l'Ardea pubes fait passer les Laurentia nomina au-delà des Pyrénées (Sil., I, 667 sq.), considérant ainsi les Rutules comme les proches parents des Laurentes. Cette parenté avec les Latins est confirmée par la généalogie de Turnus, qui est présenté comme consanguineus de Latinus (Virg., En., VII, 367; XII, 29), étant donné qu'il est le neveu d'Amata (DH., I, 64, 2; Servius, En., VI, 90; VII, 366; XII, 29; OGR, XIII, 5; $8)^{33}$, voire comme un Laurente (Virg., En., VII, 650). De même, chez Denys

${ }^{29}$ Cf. D. Briquel, Le problème des Dauniens, dans MEFRA, 1974, 1, p. 7-40.

${ }^{30}$ Peut-être ne faut-il pas accorder trop d'importance à cette tradition, dans la mesure où Virgile cherche probablement ici à rappeler, avec le nom Daunus, celui du fondateur mythique d'Argos, Danaus, ancêtre de Danaé, elle-même fondatrice d'Ardée, selon les récits d'origines gentium établis sur le modèle grec. Cf. infra.

${ }^{31}$ Il est probable en réalité que Servius fasse confusion entre les contingents de Sacrani sous le commandement de Turnus, évoqués par Virgile (En., VII, 796) et la tradition qui fait partir le uer sacrum des Sacrani de la région de Réate (Fest., p. 424425 L; P. Fest., p. 425 L). Sur le uer sacrum, cf. O. de Cazanove, Sacrifier les bêtes, consacrer les hommes. Le printemps sacré italique, dans S. Verger (dir.), Rites et espaces en pays celte et méditerranéen. Étude comparée à partir du sanctuaire d'AcyRomance (Ardennes, France), Rome, 2000 (Collection de l'École française de Rome, 276), p. 253-276.

${ }^{32}$ Th. Mommsen (Histoire romaine, I, Paris, 1863, p. 47) se rattache plus ou moins à cette idée en considérant les Rutules et les Volsques comme des "peuplades ombro-sabelliques», qui ne sont pas "purement latines».

${ }^{33}$ On a fait remarquer que le nom Amata, qui apparaît chez Denys comme 'A $\mu$ í$\tau \alpha$, n'est peut-être que la transcription du latin amita, «tante», ce qui enlève toute 
(I, 64, 2), Turnus / Tyrrhénos est un Latin de la famille royale, qui passe dans le camp des Rutules à la tête des troupes qu'il commande. La mère de Turnus est Venilia (Virg., En., X, 76; 618), sœur d'Amata (Serv., En., VI, 89; VII, 366; XII, 29) ${ }^{34}$, dont le nom est à rapprocher de celui de Vénus (dont le nom étrusque, Turan, rappelle celui de Turnus) ${ }^{35}$. Virgile fait de Turnus le frère de la nymphe Juturne (En., X, 439; XII, 138) ${ }^{36}$, qui est une divinité latine, honorée aussi bien dans les Monts Albains, qu'à Lauinium et à Rome. Comme l'a bien remarqué A. Montenegro Duque, l'idée qui sous-tend le cadre ethnographique de l'Énéide de Virgile est celle d'une parenté générale, d'une unité primordiale du peuplement de la péninsule, qui préfigure l'unité de l'Italie dans le serment à Octave. En effet, tout en insistant sur la parenté entre les Latins et les Rutules, Virgile n'hésite pas, à travers des jeux onomastiques subtils à suggérer aussi bien une parenté entre Étrusques et Rutules qu'une domination rutule sur tout le Latium ${ }^{37}$. En outre, il désigne comme «Rutules» tous les guerriers qui sont coalisés sous la bannière de Turnus, ce qui tend à étendre le territoire "rutule» sur tout le Latium, en y incluant aussi bien les bords du Tibre ${ }^{38}$ et les Monts Albains

épaisseur historique au personnage. Cf. R. Crahay et J. Hubaux, Les deux Turnus, dans SMSR, XXX, 1959, p. 168. Amita désigne toutefois la sœur du père, alors que dans la tradition, Amata est la tante maternelle de Turnus. Il ne s'agirait que d'une fausse étymologie. Cf. A. La Penna, s.u. Amata (Amata), dans Enciclopedia Virgiliana, I, Rome, 1984, p. 124.

${ }^{34}$ Cf. A. Traina, art. cit. n. 22; A. Montenegro Duque, La onomástica de Virgilio y la antigüedad preitálica, I, Salamanque, 1949.

35 Cf. A. Montenegro Duque, op. cit. n. 34, p. 87, qui pense même que Venilia est une invention de Virgile, destinée à renforcer le parallèle entre Enée, fils de Vénus, et Turnus, fils de Venilia. Contra A. Carandini (La nascità di Roma. Dei, Lari, eroi e uomini all'alba di una civiltà, Turin, 1997, p. 167) qui considère la nymphe Venilia comme une très ancienne divinité du Latium; on pourrait alors supposer que Virgile se limite à jouer de l'assonance entre le nom de Vénus et celui de l'obscure Venilia.

${ }^{36}$ Le nom même de Ju-turna peut être rapproché de celui de Turnus; il s'agirait alors d'un «authentique couple divin comme on en trouve tant dans la mythologie romaine, où ils semblent résulter de la division fonctionnelle d'un même personnage». Cf. R. Crahay et J. Hubaux, art. cit. n. 33, p. 180.

${ }^{37}$ Cf. A. Montenegro Duque, op. cit. n. 34, p. 81 sq.

${ }^{38}$ Sur l'occupation d'une partie de la rive gauche du Tibre par les Rutules chez Virgile, cf. F. Della Corte, La mappa dell'Eneide, Florence, 1972, p. 190-192. Selon le récit virgilien, le territoire des Sicani, probablement celui de Ficana, appartenait à Latinus qui y avait installé des colons rutules et aurunces, dont son garde-chasse Tyrrhus et ses fils (Virg., En., VII, 485 sq .; XI, 316 sq.; Serv., En., XI, 318). Ce glissement vers le nord des Rutules chez Virgile est également rendu nécessaire par le déplacement de l'action vers la bouche du Tibre qu'effectue le poète (cf. F. Della Corte, ibid., p. 204). 
que la plaine pontine et tout le territoire des Volsques. À travers cette unité «rutule» du Latium, le poète se réfère aussi bien à l'unité de peuplement de substrat proto-historique, avec les mentions des Sicanes et des Aurunces $(E n ., \text { VII, } 794 s q .)^{39}$, qu'à une présumée domination étrusque sur le Latium et la Campanie, dont Caton se fait l'écho en évoquant le temps où les Volsques étaient soumis aux Étrusques (Or., I, 13 Chassignet ap. Serv., En., XI, 567 : in Tuscorum iure).

L'onomastique rutule se réduit pour nous à quelques noms (Ardea, $R u$ tuli, Turnus), tandis que le stock virgilien, sous-tendu par une volonté démonstrative, est le fruit d'une reconstruction savante et ne peut pas être versé directement au dossier ${ }^{40}$. Les origines des Rutules offrent donc une stratification de l'information, chaque auteur ajoutant ou retranchant un aspect, en raison des besoins de sa démonstration, qu'il cherche à exalter l'unité des peuples de la péninsule, l'importance des Étrusques dans l'histoire archaïque de l'Italie, les relations entre le Latium et la Sicile etc. Ainsi, pour exalter l'autochtonie des Latins, Tibulle n'hésite pas à qualifier Turnus et les Rutules de barbares (II, 5) ${ }^{41}$.

Au delà des sources littéraires, on peut tenter également de déterminer l'identité des Rutules à travers la documentation épigraphique, étant donné que la langue est considérée par les auteurs antiques comme un critère ethnographique valide pour distinguer des populations ${ }^{42}$. La documentation

${ }^{39}$ Cf. B. Rehm, Das geographische Bild des alten Italien in Vergils Aeneis, Leipzig, 1932 (Philologus, suppl. XXIV), p. 28.

${ }^{40}$ Cf. A. Montenegro Duque, op. cit. n. 34, p. 106 sq. Les noms des guerriers «rutules» de l'armée de Turnus sont formés en vertu de plusieurs mécanismes : ils peuvent dériver soit de toponymes (Vfens, Massicus), renvoyant en général au territoire volsque, à la Cisalpine, à l'Étrurie (Atinas, Camers, Alsus), à la Sicile voire à l'Espagne, soit de noms de familles romaines de l'époque du poète, qu'il s'agit de glorifier en les évoquant dans l'épopée (Ilus pour les Iulii, Cethegus pour les Cornelii, Clausus pour les Claudii). Tous ces noms sont donnés sous des formes «archaïsantes» ou hellénisantes (Thymber, Cydon, Rhoetus).

${ }^{41}$ La même volonté de distinguer les Rutules comme une population barbare, étrangère, se retrouve chez Apulée (Socr., I, 5).

${ }^{42}$ Les Anciens considéraient qu'à chaque peuple correspondait une langue, comme l'indiquent entre autres Hérodote (III, 98) et Aulu-Gelle (XVII, 17, 2). Il s'agit toutefois plus d'un principe que d'une réalité : ainsi, Denys d'Halicarnasse considère que les Samnites, les Bruttiens et les Opiques parlent des langues différentes (DH., I, $89,3)$. Or, nous savons que ces trois peuples parlaient l'osque. Denys, qui considère que les populations apparentées se reconnaissent à leur ó $\mu$ o $\omega v i ́ \alpha$ (I, 29, 3-4), est victime de son propre raisonnement : comme il s'agit de peuples distincts, il en déduit qu'ils parlent des langues distinctes. Cf. S. Bourdin, Peuples et conflits territoriaux en Italie centrale et septentrionale au $I V^{e}$ siècle av. J.-C., Aix-en-Provence, 2003, thèse de doctorat dactylographiée, p. $605 \mathrm{sq}$. 
est malheureusement très réduite. L'inscription $C I L \mathrm{I}^{2}, 474$ sur le pied d'un

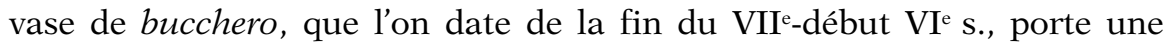
marque de propriété : eqo k. anaios, soit ego K(aeso) Annaeus ${ }^{43}$. Récemment, H. Solin a proposé une nouvelle lecture : eqo kavidios, qui semble plus probable ${ }^{44}$. Elle provient des bords du fosso dell'Incastro, "sous le château » ${ }^{45}$, ce qui correspond au palazzo signorile médiéval, aujourd'hui détruit, qui flanquait le mur d'enceinte de l'acropole ${ }^{46}$. Cette inscription, avec eqo comme graphie archaïque pour ego, est indéniablement latine et on peut la comparer à une autre inscription sur une patère de bucchero $\left(C I L, \mathrm{I}^{2}, 479\right.$ : eqo fulfios $)^{47}$. Deux autres inscriptions sur vase, reconnues dans un premier temps comme "falisques", peuvent être considérées également comme des inscriptions latines, du latin dialectal que l'on parlait à Ardée ${ }^{48}$. Elles proviennent d'une tombe située immédiatement à l'extérieur du second agger d'Ardée, sur le plateau de Casalazzaro ${ }^{49}$. La première, sur un bol, se lit titoio (Ve. 364)

${ }^{43}$ Cf. G. Colonna, La diffusione della scrittura, dans Civiltà del Lazio primitivo. Palazzo delle esposizioni. Roma 1976, Rome, 1976, p. 372.

${ }^{44}$ En effet, pour une époque aussi précoce, les vases portent en général des noms individuels et non des formules bimembres, et surtout pas avec le prénom abrégé. Selon H. Rix, on aurait par la suite le passage Gavidios > Gavios > Gaius. Cf. H. Solin, La nascita del cognomen a Roma, dans L'onomastica dell'Italia antica : aspetti linguistici, storico-culturali, tipologici e classificatori, Atti del convegno Roma 13-16 novembre 2002, s. p. et intervention successive d'H. Rix.

${ }^{45}$ Cf. NSA, 1882, p. 273.

${ }^{46}$ Cf. L. Spera, Via Ardeatina, Rome, 2002, p. 87. Un château et une tour, appartenant au monastère de Saint-Paul-hors-les-Murs, sont mentionnés dans une bulle de Grégoire VII de 1074. Cf. A. Nibby, Analisi storico-topografico-antiquaria della carta de' dintorni di Roma, 1, Rome, 1849 (2ééd.), p. 231.

${ }^{47}$ Même si cette inscription a été considérée parfois comme falisque (cf. G. Giacomelli, La lingua falisca, Florence, 1963), notamment en raison de la forme des caractères et du mot eqo, que l'on retrouve dans une inscription de Civita Castellana (CIE 8079 = LF 1; cf. G. Giacomelli, art. cit. n. 12, p. 525), elle est désormais reconnue comme latine (cf. D. Briquel, art. cit. n. 29, p. 37).

${ }^{48}$ On sait que le latin de Préneste, par exemple, est sensiblement différent du latin de Rome (cf. M. Mancini, Tracce di interferenza fra etrusco e latino a Preneste, dans SE, LXIII, 1997 (1999), p. 315-345). Certains considèrent même que le falisque n'est qu'un dialecte séparé du latin du Latium par l'installation de groupes sabins dans la zone de Capène (cf. G. Colonna, I Latini e gli altri popoli del Lazio, dans Italia omnium terrarum alumna. La civiltà dei Veneti, Reti, Liguri, Celti, Piceni, Umbri, Latini, Campani e Iapigi, Milan, 1988, p. 412).

${ }^{49}$ Cf. A. Pasqui, Ardea (comune di Genzano) : scavi della necropoli ardeatina, dans NSA, 1900, p. 53-69. Les deux inscriptions proviennent de la tombe Q, à fosse, contenant deux dépositions séparées par une cloison interne, avec les deux défunts probablement déposés dans des cercueils de bois. Le mobilier se composait de deux miroirs de bronze, d'un bol, d'un simpulum et d'un petit bol à bord rentrant à vernis 
et la seconde, sur un plat, neuen : deuio (Ve. $364 \mathrm{~b}=C I L, \mathrm{I}^{2}, 455$ ), que l'on a proposé d'interpréter comme nouem deum ${ }^{50}$. D'autres inscriptions latines sont connues par la suite à Ardée, avec notamment une dédicace à Hercule (HERCOLEI) sur une écuelle du $\mathrm{II}^{\mathrm{e}} \mathrm{s}$. av. J.-C., provenant du temple du forum $^{51}$ ou une inscription de dédicace sur un cratérisque de la fin du $\mathrm{IV}^{\mathrm{e}}$-début du III ${ }^{\mathrm{e}}$ s., découvert en $1852\left(C I L, \mathrm{I}^{2}, 358\right)^{52}$. La participation d'Ardée aux sacrifices à Jupiter Latiaris, sur le Mont Albain est en outre documentée par une autre inscription latine, découverte en 1869 : diu(u)ei / Ardeates, soit Ioui Ardeates $\left(C I L, \mathrm{I}^{2}, 39=\mathrm{VI}, 2020=\mathrm{XIV}, 2231\right)^{53}$.

Plus récemment, on a découvert une inscription de defixio sur une lamelle de plomb, dans le secteur du sanctuaire de Colle della Noce. Elle provient d'une couche contenant du matériel daté entre le dernier quart du VIII'-premier quart du VII ${ }^{e}$ s. et la fin du IV e s. av. J.-C. G. Colonna propose de la dater du second quart du Ve $\mathrm{V}^{54}$. Cette inscription est rédigée en étrusque : vel uAraś / mlax; il s'agit d'une formule onomastique au nominatif, avec le prénom bien connu Vel et le gentilice Uthra(s), qui renvoie au gentilice Utre(s) de San Giovenale (ET AT 2.4), tandis que l'adjectif mlax, déjà connu en étrusque ${ }^{55}$, rappelle le grec $M \alpha \lambda \alpha \kappa o ́ \varsigma$ et correspond à un sur-

noir, du bol à vernis rouge avec l'inscription titoio, du plat portant la $2^{\mathrm{e}}$ inscription, d'une petite amphore d'argile fine et d'un peson de métier à tisser.

${ }^{50}$ Cf. G. Giacomelli, op. cit. n. 47, p. 262-263. Le génitif en -oio peut être considéré comme une évolution à partir du génitif archaïque en -osio, que l'on rencontre aussi bien en falisque qu'en latin (Lapis Satricanus), voire en lépontique. Cf. M. Lejeune, Notes de linguistique italique. XXXIX. Génitifs en -osio et génitifs en -i, dans REL, 67, 1989, p. 63-77.

${ }^{51}$ Cf. C. Morselli, E. Tortorici, Ardea. Forma Italiae. Regio I-volumen XVI, Florence, 1982 , p. 30.

${ }^{52}$ Cf. également A. Fabretti, Corpus Inscriptionum Italicarum ..., Turin, 1867, $\mathrm{n}^{\circ}$ 2731. L'inscription est d'une lecture difficile : ]omo. fameliai. donom. d[edet. Fameliai (= familia en latin standard) est à rapprocher de famel, qui désignerait l'esclave en osque, selon Festus (p. 77 L) et aussi des Famuli diui mentionnés dans les Actes des frères Arvales (CIL, VI, 2099). Cf. E. De Ruggiero, Dizionario epigrafico di antichità romane, III, Rome, 1906, s.u.

${ }^{53}$ Le premier terme est d'interprétation difficile; dans les volumes VI et XIV du $C I L$, on proposait une première restitution en $[$ rest $]$ itue $[$ runt $]$. Cf. aussi E. De Ruggiero, op. cit. 52, I, Rome, 1895, s.u. Ardea. Quoi qu'il en soit, pour notre propos, c'est surtout l'attestation de la participation des Ardeates au culte albain, qui est indéniable, qui importe.

${ }^{54}$ Cf. G. Colonna, F. Di Mario, Ardea, dans REE, SE, LXIX, 2003, p. 337-347.

${ }^{55}$ Cf. les dédicaces $E T$ Cr 2.27; 2.9; 2.33; 2.36; Ta 2.1. Le terme apparaît également de façon répétée dans le texte de la Momie de Zagreb (ET LL III.19; IV.15; V.11 etc.). Cf. G. Colonna, dans REE, SE, LXV-LXVIII, 2002, p. 356-357. 
nom du personnage, «le bon / le beau». Comme l'a bien noté G. Colonna, cette inscription implique la présence à Ardée d'au moins deux Étrusques, l'auteur de l'inscription, qui s'exprime en langue étrusque, et la victime du rituel, qui porte une formule onomastique étrusque. Il ne faut toutefois pas y voir une confirmation de l'origine étrusque des Rutules. En effet, on retrouve d'autres inscriptions étrusques à la même époque dans d'autres centres du Latium, aussi bien dans des tombes comme à Préneste et à Lauinium $^{56}$, que dans des sanctuaires comme à Satricum et à Rome même ${ }^{57}$. Il faut plutôt le considérer comme un signe de la mobilité des élites - comme l'indique le fait qu'il s'agisse d'une formule trimembre - qui voit, dans le courant du $\mathrm{V}^{\mathrm{e}} \mathrm{s}$., des familles étrusques ou sabines s'agréger au patriciat romain ${ }^{58}$, tandis qu'on retrouve des gens d'origine latine ou italique parmi les défunts de la nécropole étrusque de Crocefisso del Tufo à Orvieto $^{59}$.

${ }^{56}$ A Lauinium, l'inscription CIE 8612 (mini m[ulu]vanice mamar.ce a.puniie, "Mamarce Apunie m'a donné») se trouve sur une amphore de bucchero (v. 570) provenant d'une tombe à chambre. Le même individu se signale par une dédicace identique dans le sanctuaire de Portonaccio à Véies (ET Ve 3.5; début VI ${ }^{\mathrm{e}} \mathrm{s}$.). À Préneste, la tombe Bernardini a livré, outre l'inscription latine de la fibule en or, une coupe d'argent portant le nom étrusque vetusia (CIE 8614), qui était peut-être l'épouse étrusque du personnage enseveli dans la tombe. Cf. G. Colonna, art. cit. n. 43, p. 374. Le nom peut en effet être considéré comme une variante du latin Veturia au nominatif ou plutôt comme une forme étrusque au génitif en -(a)ia.

${ }^{57}$ A Satricum, l'inscription ET La 3.1 (fin VII ${ }^{\mathrm{e}}$-début $\mathrm{VI}^{\mathrm{e}} \mathrm{s}$.) indique la dédicace

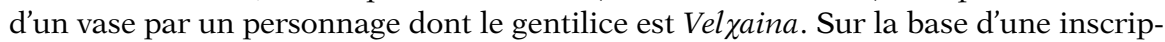
tion sur une coupe de bucchero de Caere (ET Cr 3.10: mi mulu larisale vel xainas), on a proposé d'identifier les deux personnages et de reconstruire l'inscription de Satricum en mi mu[lu larisal] vel xainasi («Laris Velchaina m’a donné»). Cf. A. Naso, art. cit. n. 26, p. 229. À Rome, dans le sanctuaire de Sant'Omobono, on a découvert une tessère d'hospitalité qui date du $2^{\mathrm{e}}$ quart du $\mathrm{VI}^{\mathrm{e}} \mathrm{s}$. et porte l'inscription ET La 2.3 : araz silqtenas spurianas (cf. M. Cristofani, La grande Roma dei Tarquini. Catalogo della mostra. Roma, Palazzo delle Esposizioni. 12 giugno-30 settembre 1990, Rome, 1990, p. 21; M. Pallottino, Origini e storia primitiva di Roma, Milan, 1993, p. 208). En tout, on connaît 8 inscriptions étrusques à Rome : des inscriptions votives, provenant de Sant'Omobono (ET La 2.2, 2.3, 2.4) des VII ${ }^{\mathrm{e}-V I} \mathrm{I}^{\mathrm{e}}$ s., du Palatin (ET La 2.5, CIE 8604), de la Cloaca Maxima (ET La 0.1, $2^{\mathrm{e}}$ moitié du VI ${ }^{\mathrm{e}} \mathrm{s}$.), de la nécropole de l'Esquilin (CIE 8608). Les deux inscriptions sur vase ET La 6.1 (vel numnal) et La 6.2 (pultuceś), provenant de l'Esquilin, sont plus récentes (fin $\mathrm{III}^{\mathrm{e}}$-milieu $\mathrm{II}^{\mathrm{e}} \mathrm{s}$.), de même que l'inscription śupluś sur une patère à vernis noir du Palatin (CIE 8606, III ${ }^{\mathrm{e}} \mathrm{s}$.).

${ }^{58}$ Cf. P.-C. Ranouil, Recherches sur le patriciat (509-366 avant J.-C.), Paris, 1975.

${ }^{59}$ Cf. C. De Simone, Le iscrizioni etrusche di Orvieto, dans Annali della Fondazione per il Museo "Claudio Faina», I, 1980, p. 27-41. Pour une recension de ces cas de mobilité, cf. S. Bourdin, op. cit. n. 42, p. 421-444. 
La situation linguistique d'Ardée à l'époque archaïque n'est donc pas très différente de celle que l'on rencontre dans le reste du Latium. Il semble que les Rutules d'Ardée parlent latin, au moins depuis l'apparition de l'écriture dans la région, et que l'on rencontre dans la population d'Ardée une certaine proportion d'étruscophones, selon un schéma que l'on retrouve à Rome, à Lauinium ${ }^{60}$, à Satricum et à Préneste et que l'on peut donc considérer comme représentatif des grandes cités latines de l'époque ${ }^{61}$.

L'examen de la documentation archéologique renforce cette idée d'une identité latine des Rutules d'Ardée. En effet, les archéologues considèrent habituellement - et parfois de façon arbitraire - que les cultures matérielles, les faciès archéologiques, correspondent à des différences ethniques. Ainsi, pour le début de l'Âge du Fer, on associe la culture villanovienne aux groupes qui sont définis, dans un second moment, comme «étrusques», tandis que la culture latiale est considérée comme l'expression matérielle des populations «latines ${ }^{62}$. La fréquentation du site d'Ardée remonte à l'Âge du Bronze moyen (apenninique) et on connaît notamment du matériel provenant des pentes N.O. de l'acropole, ainsi que deux tombes a pozzetto du Bronze final à la localité Campo del Fico ${ }^{63}$. Ardée appartient alors à un vaste faciès culturel commun à l'Italie centrale ${ }^{64}$, qui se

${ }^{60}$ C'est à Lauinium notamment que se retire l'étrusque Tarquin Collatin après son abdication du consulat en 509 (Liv., II, 2, 10; DH., V, 12, 3; VIII, 49, 6). Cf. F. Castagnoli (dir.), Lavinium I. Topografia generale, fonti e storia delle ricerche, Rome, 1972, p. 101.

${ }^{61}$ Cette présence physique d'Étrusques dans les villes du Latium est parallèle à la diffusion de productions étrusques, en particulier du bucchero, que l'on rencontre dans les principaux centres latins, dont Ardée, où on connaît des tombes qui ont livré des alabastres corinthiens et étrusco-corinthiens (fin $\mathrm{VII}^{\mathrm{e}}$-début $\mathrm{VI}^{\mathrm{e}} \mathrm{s}$.) et du bucchero étrusque. Cf. R. M. Cook et C. B. R. Butchart, Some bucchero vases from Ardea, dans PBSR, XVII, 1949, p. 1-4.

${ }^{62} \mathrm{Cf}$. en dernier lieu la synthèse d'A. Grandazzi, Les origines de Rome, Paris, 2003, p. $51 s q$., part. p. 56 : «...la culture latiale est l'expression archéologique de populations implantées depuis longtemps dans la région et parlant le latin.»

${ }^{63}$ Pour une présentation synthétique du matériel découvert à Ardée, on se reportera à P. G. Gierow, The Iron Age Culture of Latium. I. Classification and Analysis, Lund, 1966 et à C. Morselli et E. Tortorici, op. cit. n. 51, p. 32 sq. Dans le même secteur, on a fouillé aussi 8 tombes de l'Âge du Fer, dont le matériel rappelle les tombes de Castel di Decima.

${ }^{64} C^{\prime}$ est ce qu'indique également le dépôt métallique découvert à la localité Rimessone ( $2^{\mathrm{e}}$ moitié $\mathrm{XI}^{\mathrm{e}} \mathrm{s}$.), près d'Ardée, dont les objets présentent des parallèles avec des exemplaires d'Étrurie et d'Italie centrale. Ce dépôt précède la différenciation culturelle qui se produit à partir du $\mathrm{X}^{\mathrm{e}} \mathrm{s}$. entre Étrurie et Latium. Cf. F. Delpino et M. A. Fugazzola Delpino, Il ripostiglio del Rimessone, dans Atti della XXI Riunione 
distingue du faciès de Grotta Nuova que l'on rencontre au sud d'Anzio ${ }^{65}$. Pour les phases latiales I-III, on connaît des vestiges de cabanes dans plusieurs endroits de l'acropole et de la localité Civitavecchia ${ }^{66}$, ainsi qu'un dépôt métallique formé de 85 fibules et 206 haches de bronze, datant du milieu du VIII ${ }^{\mathrm{e}} \mathrm{s} .{ }^{67}$. Ce matériel appartient à la culture latiale, qui est commune à Ardée et à tout le Latium uetus. Par la suite, l'évolution d'Ardée suit sensiblement les grandes phases du développement des cités latines, en étant tout à fait comparable à la situation de Lauinium, distante seulement de $8 \mathrm{~km}$ à vol d'oiseau. Dès le latial IV B (milieu VIII ${ }^{\mathrm{e}} \mathrm{s}$ ), Ardée évolue dans un sens urbain et se dote dans le courant du VII ${ }^{\mathrm{e}} \mathrm{s}$. d'un complexe de fortifications - agger et fossé -, qui rappellent les exemples contemporains de Lauinium, Antium et Satricum ${ }^{68}$. Les décorations des trois temples archaïques connus à Ardée s'intègrent parfaitement dans le cadre culturel de la région et renvoient à des exemplaires comparables connus à Véies, Velletri ou Satricum ${ }^{69}$. Rien dans son organisation, telle qu'elle nous apparaît à travers les vestiges archéologiques, ne distingue donc Ardée, qui connaît un développement continu depuis le Bronze moyen jusqu'à l'époque historique $^{70}$, des autres métropoles du Latium uetus. D’un strict point de vue archéologique donc, les Rutules d'Ardée doivent être considérés comme des Latins, ce qui n'a rien d'étonnant, dans la mesure où, rappelons-le, Ardée est située en plein cœur du Latium uetus : elle est distante, à vol d'oiseau, de $8 \mathrm{~km}$ de Lauinium, de $15 \mathrm{~km}$ d'Aricie, de $19 \mathrm{~km}$ d'Antium, de $20 \mathrm{~km}$ de Satricum et de $21 \mathrm{~km}$ du sanctuaire de Jupiter sur le mont Albain, centre religieux de la ligue latine.

scientifica. Il Bronzo finale in Italia. Firenze 21-23 ottobre 1977. In memoria di Ferrante Rittatore Vonwiller, Florence, 1979, p. 425-452.

${ }^{65}$ Cf. A. Guidi, P. Pascucci et A. Zarattini, Confini geografici e confini culturali : le facies della preistoria e della protostoria nel Lazio meridionale, dans Latium, 19, 2002, p. 16.

${ }^{66}$ Cf. P. G. Gierow, op. cit. n. 63, p. 17-22. Le matériel de ces deux secteurs, conservé au Museo Pigorini, a été mélangé, ce qui ne permet pas de distinguer d'éventuelles phases.

${ }^{67}$ Cf. R. Peroni, Considerazioni ed ipotesi sul ripostiglio di Ardea, dans BPI, 75, 1966, p. 175-197 et A. M. Bietti Sestieri, Ardea, dans Civiltà del Lazio primitivo... cit. n. 43 , p. $312-314$.

${ }^{68}$ Cette fortification est renforcée dans un second moment, probablement au $\mathrm{IV}^{\mathrm{e}} \mathrm{s}$. av. J.-C. par un mur de soutènement en opus quadratum.

${ }^{69}$ Cf. G. Manca Di Mores, Terrecotte architettoniche dai templi di Ardea, dans QAEI, 21, 1993, p. 311-314.

${ }^{70}$ Ardée partage cette particularité notamment avec Rome et Lauinium. Cf. M. A. Fugazzola Delpino, Le fasi culturali della protostoria laziale, dans Civiltà del Lazio primitivo... cit. n. 43, p. 17-18. 
La documentation épigraphique et archéologique, de même qu'une partie des auteurs antiques eux-mêmes, induisent à intégrer les Rutules parmi les populations du Latium. Mais doit-on les considérer simplement comme des Latins (portant un nom différent) ou comme une population proche des Latins mais distincte? A. Montenegro Duque concluait son étude sur l'onomastique des Rutules chez Virgile, en déclarant que cette question demeurait difficile à trancher ${ }^{71}$. La solution proposée par M. Pallottino est selon nous la plus vraisemblable ${ }^{72}$ : dans une phase initiale, le Latium est occupé par une pluralité de populations, parmi lesquelles on peut identifier les Albenses dans la zone des Monts Albains, les Prisci Latini dans la région basse entre le Tibre et l'Anio - probablement ceux que Cicéron désigne par la suite comme Latinienses, pour éviter les confusions avec le terme Latini qui a pris alors une acception plus large ${ }^{73}-$, les Laurentes, sur la côte entre le Tibre et le Numicus, les Rutuli dans la zone de la future Ardée. Ces populations sont elles-mêmes articulées en petits groupes, à l'économie essentiellement pastorale, les populi, regroupés dans des «fédérations» autour de cultes communs, comme le culte de Jupiter Latiaris pour les populi Albenses de la liste de Pline l'Ancien (III, 69) ${ }^{74}$ ou les populi du Septimontium sur le site de la future Rome (Varr., L., V, 41; VI, 24; Fest., $458 \mathrm{~L} ; 476 \mathrm{~L})^{75}$. Dans un second temps, l'urbanisation s'affirme et certains populi disparaissent en se fondant dans des ensembles plus vastes, comme les Velienses et les Foreti à Rome ${ }^{76}$; certains ethnonymes s'étendent (Latini),

${ }^{71}$ Cf. A. Montenegro Duque, op. cit. n. 34, p. 134. Il

${ }^{72}$ Cf. M. Pallottino, Inquadramento storico, dans Civiltà del Lazio... cit. n. 43, p. 39-42 et Stirpi e lingue nel Lazio e intorno al Lazio in età arcaica, dans QAEI, 15, 1987, p. 179-184.

${ }^{73}$ Cf. H. Solin, art. cit. n. 2.

${ }^{74}$ Cette liste présente les populations du Latium à un stade de développement pré-urbain. On constate l'absence des Laurentes et des Rutules, alors que les Latinienses y sont mentionnés. Pour A. Grandazzi (La liste plinienne des populi dits Albenses (Nat. Hist. III, 69) : anciennes et nouvelles hypothèses, dans REL, 77, 1999 (2000), p. 30-49), les Numicienses correspondraient aux habitants des futures Lauinium et Ardée. On peut aussi rapprocher les Sacranes de la liste des Sacrani de Virgile et y voir des «proto-Rutules». L'identité «rutule» apparaîtrait donc dans un second temps par rapport à celle des Albenses. Cependant, les manuscrits portent $\mathrm{Nu}$ minienses (ou Numimses) et la lecture Numicienses d'A. Grandazzi n'est qu'une hypothèse.

${ }^{75}$ Cf. D. Briquel, La lente genèse d'une cité, dans F. Hinard (dir.), Histoire romaine. 1. Des origines à Auguste, Paris, 2000, p. 61-63.

${ }^{76}$ Cf. R. A. Palmer, The archaic community of the Romans, Cambridge, 1970, p. 76 . 
tandis que d'autres disparaissent (Albenses) ou se réduisent aux dimensions d'un populus (Laurentes, Rutuli). Le nom de Latini s'est étendu à l'ensemble probablement avec la mise sur pied de la ligue latine, qui englobe les Prisci Latini et les Albenses ${ }^{77}$; mais, il reste à expliquer les raisons du maintien, même dans des dimensions réduites, des autres ethniques, Laurentes et $R u$ tuli, alors que les cités de Lauinium et Ardea faisaient partie indéniablement de la ligue latine.

\section{ArdéE et les Rutules : LES donNÉES HistoriQues}

\section{Les Rutules et Ardée indépendante}

Pour les auteurs antiques, il ne fait pas de doute que les Rutules sont une réalité très ancienne du peuplement de la Péninsule. Cicéron précise ainsi que Rome, au moment de sa fondation, était entourée par les Aborigènes et les Rutules (Rep., II, 5). Les Rutules apparaissent plusieurs fois dans le récit de la période royale, comme quand Festus rapporte que les Luceres tiennent leur nom du roi d'Ardée Lucerus, qui aurait aidé Romulus dans la guerre contre Titus Tatius (P. Fest., p. 106 L). À cette même tradition antiquaire à propos de l'influence d'Ardée sur le développement de Rome, nous pouvons rattacher la notice sur l'emprunt des fétiaux soit aux Équicoles, soit aux Ardéates (Cn. Gellius, frg. 16 Chassignet, ap. DH., II, 72, 1-3). Pour les auteurs latins donc, Ardée est une ville puissante et influente dès les premiers temps de l'Vrbs et la documentation archéologique ne contredit pas cette impression ${ }^{78}$. C'est à cette importance d'Ardée dans

${ }^{77}$ On peut presque penser que le récit de la destruction d'Albe, qui n'a probablement jamais existé en tant que ville, mais uniquement comme un regroupement de villages et de populations dispersées (cf. S. Quilici Gigli, A proposito delle ricerche sull'ubicazione di Alba Longa, dans PP, CCIX, 1983, p. 140-149; A. Grandazzi, La localisation d'Albe, dans MEFRA, 98, 1, 1986, p. 47-90), n'est qu'un symbole de la disparition de l'identité d'Albenses, englobée dans celle, plus large, de Latini. J. Poucet a fait remarquer que les données ne coïncident pas : la crise du peuplement de la zone albaine est datée du milieu du IX ${ }^{\mathrm{e}}$ s., alors que la «destruction» d'Albe se produirait vers 650; le motif de la destruction, inspiré de l'Ilioupersis, ne servirait qu'à expliquer l'absence d'une cité d'Albe à l'époque historique (cf. J. Poucet, Les origines de Rome. Tradition et histoire, Bruxelles, 1985, p. 147-149).

${ }^{78}$ Pour la documentation archéologique d'Ardée et la reconstitution des grandes phases de son développement, on se reportera principalement à Enea nel Lazio. Archeologia e mito. Bimillenario virgiliano. Roma 22 settembre-31 dicembre 1981. Campidoglio-Palazzo dei Conservatori, Rome, 1981, p. 10-16; C. Morselli, E. Tortorici, op. cit. n. 51; F. Coarelli, Lazio, Rome-Bari, 1982 (Guide archeologiche Laterza), p. 282-287; L. Crescenzi et E. Tortorici, Scavi ad Ardea, dans QAEI, 7, 1983, p. 38- 
l'histoire archaïque de Rome qu'il faut rattacher la notice sur le uer sacrum des Sacrani, venus à Rome depuis Ardée (Serv., En., VII, 796).

Le site d'Ardée se compose d'un vaste plateau de tuf, au confluent du Fosso della Mola et du Fosso dell'Acquabona, subdivisé en trois parties : la pointe méridionale, où se trouve l'habitat actuel, est considérée comme la plus ancienne zone d'occupation et appelée conventionnellement "acropole». Cependant, on sait que l'occupation du plateau de Civitavecchia, immédiatement au nord, remonte également au Bronze moyen, tandis que pour la localité Casalazzara (ou Casalazzaro), on suppose une occupation plus discontinue. Dès le VII ${ }^{e}$ s., Ardée se dote d'un complexe défensif, centré sur deux levées de terre (agger) doublées d'un fossé, l'un au nord de Casalazzara et l'autre au nord de Civitavecchia ${ }^{79}$. Après de nombreux débats sur la datation de ces structures et sur l'existence même du second agger, l'accord semble s'être fait autour de l'idée d'un système de défense formé sur trois aggeres et fossés, le troisième protégeant l'acropole ${ }^{80}$. Dès cette période, le plateau est traversé par un axe longitudinal, qui part en direction des Monts Albains. L'évolution d'Ardée est tout à fait comparable à celle de Lauinium, à laquelle les sources attribuent également une grande importance dans le récit de la Rome royale ${ }^{81}$.

La prospérité d'Ardée à l'époque est illustrée notamment par les décorations de ses temples. On connaît trois temples archaïques, un sur l'acropole, que l'on interprète par convention comme le sanctuaire de Junon

47; Id., Il caso di Ardea, dans QAEI, 8, 1984, p. 345-350; R. Pierobon, s.u. Ardea, dans BTCGI, IV, Pise-Rome, IV, 1984, p. 278-292; L. Quilici et S. Quilici Gigli, I Volsci. Testimonianze e leggende, Rome, 1997. Pour les vestiges sur le territoire autour d'Ardée, cf. L. Crescenzi, L. Quilici et S. Quilici Gigli, Carta archeologica del comune di Ardea, dans RIA, XVIII, 1971, p. 5-46; F. Melis et S. Quilici Gigli, Luoghi di culto nel territorio di Ardea, dans ArchClass, XXXIV, 1982, p. 1-37, pl. I-VIII; L. Quilici et S. Quilici Gigli, Attività estrattiva dello zolfo nella zona tra Ardea ed Anzio, dans QAEI, 8, 1984, p. 229-249; L. Spera, op. cit. n. 46.

${ }^{79}$ La présence d'un second agger au nord de Casalazzara a été fortement contestée (cf. C. Caprino, s.u. Ardea, dans EAA, I, 1958, p. 600), mais on tend actuellement à accepter son existence sur la base des travaux de L. Quilici (A proposito del secondo aggere di Ardea, dans ArchClass, XX, 1, 1968, p. 137-140).

${ }^{80}$ Cf. C. Morselli et E. Tortorici, op. cit. n. 51, p. 32. Pour le débat autour de la datation des fortifications, cf. A. Boëthius, Le fortificazione di Ardea, dans Orom, IV, 1962, p. 29-43; L. Quilici, art. cit. n. 79. Le fossé de l'acropole, aujourd'hui comblé, était encore visible dans les années 1960 (cf. photo dans A. Boëthius, art. cit. supra, p. 42).

${ }^{81}$ On le voit notamment dans les notices qui situent à Lauinium l'assassinat de Titus Tatius et qui font remonter au règne de Romulus les liens religieux entre les deux villes latines (DH., II, 52; Plut., Rom., 23, 1-3). 
Reine, un sur le forum à Civitavecchia et un à la localité Colle della Noce ${ }^{82}$. Les plus anciennes décorations du temple de l'acropole remontent au $\mathrm{VI}^{\mathrm{e}}$ s., avec des plaques de terre cuite rappelant les exemplaires de Véies et Velletri $^{83}$. Le temple de la Civitavecchia semble légèrement plus récent, avec une série de plaques de revêtement, couronnements et antéfixes qui rappellent ceux de la deuxième phase du temple de Mater Matuta à Satricum (490-480). Les décorations les plus anciennes du temple de Colle della Noce, en revanche, remontent au milieu du $\mathrm{V}^{\mathrm{e}} \mathrm{s}$. et sa construction a été mise en relation avec la déduction de la colonie en 442 . Il est probable qu'à cette occasion la décoration des deux autres temples ait été restaurée ${ }^{84}$.

L'importance de la ville et de ses fortifications transparaît de même dans le récit annalistique. En effet, Tarquin le Superbe, guignant la prospérité des Rutules, vient assiéger Ardée et c'est à cette occasion, en 509, que se produit l'épisode du viol de Lucrèce : Sextus Tarquin, le fils du roi, quitte le camp et se rend à Collatie, où il abuse de Lucrèce, épouse de son cousin Tarquin Collatin; celle-ci se donne la mort sous les yeux de son père Lucretius et de Brutus, ce qui provoque la chute de la monarchie à Rome (Liv., I, 57; DH., IV, 7; 64; DC. II; Vir ill., 8, 5; Zon., VII, 11). À cette occasion, Tite-Live précise bien que Tarquin s'est résolu au siège parce qu'il ne parvenait pas à prendre la ville d'assaut. D'une manière générale, les sources insistent sur la longueur du siège (Ov., F., II, 721-722; 727 sq.; 749 $s q$.) et divergent ensuite quant au sort d'Ardée. Pour Denys, après l'expulsion des Tarquins, les consuls Horatius et Herminius font la paix avec Ardée pour 15 ans $(\mathrm{IV}, 85 ; \mathrm{V}, 1,2)$, tandis que chez les auteurs plus tardifs,

${ }^{82}$ Il s'agirait du temple de Junon sur l'acropole, d'Hercule sur le forum et des Dioscures à Colle della Noce. Cf. G. Colonna, I templi nel Lazio fino al $V$ secolo compreso, dans QAEI, 8, 1984, p. 409.

${ }^{83}$ Ardée est insérée dans le mouvement général qui voit l'émergence des grands temples latiaux, dans la seconde moitié du VI'e s., comme à Rome (Sant'Omobono), Lauinium, Satricum etc. Certains de ces sanctuaires se superposent à des cabanes proto-historiques antérieures, comme le temple du Colle della Noce (cf. aussi Gabies, 13 autels à Lauinium). Cf. G. Colonna, art. cit. n. 82, p. 396-411 et M. Torelli, I culti, dans QAEI, 8, 1984, p. 412 sq.

${ }^{84}$ Cf. G. Manca Di Morres, art. cit. n. 69, p. 311-314. C'est l'unique temple d'Ardée pour lequel nous possédions une documentation de fouille récente et bien publiée (Cf. L. Crescenzi et E. Tortirici, art. cit. n. 78). Le temple repose sur des niveaux proto-historiques, qui ont livré plusieurs tombes à fosse (dont une qui date du début du $\mathrm{VI}^{e}$ s. et sert de $T P Q$ pour la construction du temple) et des fonds de cabanes. La fouille d'un dépôt votif a en outre permis de récupérer de nombreux fragments de décorations architectoniques qui attestent les fréquentes restaurations du sanctuaire jusqu'au $\mathrm{II}^{\mathrm{e}}$ s. av. J.-C. 
nous rencontrons des allusions à une conquête d'Ardée par le tyran (Sen, Ep., XIV, 91, 16; Flor., I, 1; Oros., Hist., II, 4, 12).

La version de Denys semble préférable, dans la mesure où Ardée est mentionnée peu après dans le traité romano-carthaginois de 508 (Pol., III, 22), dont l'authenticité est actuellement acceptée ${ }^{85}$. Le traité établit la $\varphi \imath \lambda i ́ \alpha$ entre d'une part les Romains et leurs alliés et d'autre part les Carthaginois; les Romains s'engagent à ne pas dépasser le Beau Promontoire et le commerce est réglementé. Les Carthaginois s'engagent de leur côté à ne faire de tort ni aux Ardéates, ni aux Antiates, ni aux Larentinoi ( $\Lambda \alpha \rho \varepsilon v-$

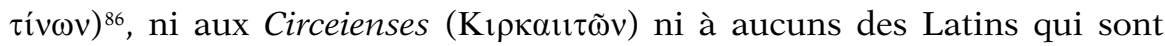
úđíкoor des Romains. Deux lectures sont alors possibles : soit l'on considère que tous les sites mentionnés sont sujets des Romains, soit que les 4 centres mentionnés en premier lieu sont distingués des "sujets».

La fidélité d'Ardée à Rome est toutefois de courte durée. Après la chute des Tarquins à Rome, l'emprise romaine sur le Latium semble se desserrer et l'on voit les Latins, guidés par Aricie, résister victorieusement à la tentative de Porsenna de les soumettre. Aricie promeut le sanctuaire de Diane Nemorensis ${ }^{87}$, sur son territoire, comme nouveau sanctuaire "fédéral»,

${ }^{85}$ Cf. B. Scardigli (dir.), I trattati romano-cartaginesi, Pise, 1991, p. 23 sq.

${ }^{86}$ L'identité des Larentinoi est controversée et nous suivrons l'opinion de F. W. Walbank qui rejette la correction habituelle en Laurentinoi, qui a le défaut de rompre la succession géographique des toponymes. Cet ordre géographique est respecté encore dans le traité suivant qui mentionne Ardée, Antium, Circeii et Terracine (Pol., III, 24, 16). La leçon des manuscrits est $\alpha \rho \varepsilon v \tau i ́ v \omega v$, qui est généralement corri-

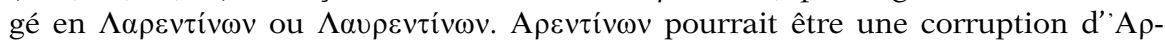

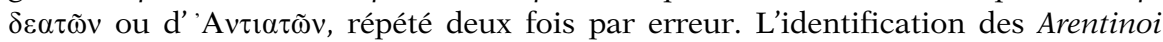
avec les Laurentes de Lauinium est donc en général rejetée. Cf. F. W. Walbank, $A$ historical commentary on Polybius. I. Commentary on Books I-VI, Oxford, 1957, p. 344-345.

${ }^{87} \mathrm{Ce}$ culte est très ancien, puisqu'on en attribue la fondation à Oreste (dont le lien avec Nemi, par l'intermédiaire de Cumes, remonterait aux $\mathrm{VI}^{\mathrm{e}}-\mathrm{V}^{\mathrm{e}} \mathrm{s}$., tandis que la tradition relative à Hippolyte semble plus récente, cf. F.-H. Pairault, Diana Nemorensis, déesse latine, déesse latinisée, dans MEFR, LXXXI, 1969, p. 447 sq.). En outre, il présente des caractères très archaïques, comme la sauvagerie du rite de désignation du desservant, le rex Nemorensis. Les vestiges les plus anciens du sanctuaire remontent au $\mathrm{V}^{\mathrm{e}} \mathrm{s}$., avec notamment une tête de statue de divinité de bronze (cf. F. Coarelli, Dintorni di Roma, Rome-Bari, 1981 (Guide archeologiche Laterza), p. 99). Son rôle de «sanctuaire fédéral» ne concerne qu'une courte période de l'histoire latine (cf. B. Liou-Gille, Une tentative de reconstitution historique : les cultes fédéraux de Diane Aventine à Diane Nemorensis, dans PP, 267, 1992, p. 411-438 et C. Ampolo, Boschi sacri e culti federali : l'esempio del Lazio, dans Les bois sacrés. Actes du Colloque international organisé par le Centre Jean Bérard et l'École pratique des hautes études (Ve section). Naples, 23-25 Novembre 1989, Naples, 1993, p. 160). 
pour faire pendant à celui de Diane Aventine à Rome, comme le rapporte le fragment de Caton signalé plus haut (Or., II, 28 Chassignet ap. Prisc., Gramm., IV, p. 129 H et VII, p. 337 H) : Lucum Dianium in nemore Aricino Egerius Baebius Tusculanus dedicauit dictator Latinus. Hi populi comuniter: Tusculanus, Aricinus, Lanuuinus, Laurens, Coranus, Tiburtis, Pometinus, Ardeatis Rutulus ${ }^{88}$. Le fragment fait référence à la consécration du lucus de Diane dans le bois d'Aricie, par Egerius Baebius de Tusculum, dictateur des Latins (dic(t)ator Latinus), en présence des représentants des populi Tusculanus, Aricinus, Lanuuinus, Laurens, Coranus, Tiburtis, Pometinus, Ardeatis Rutulus. On a vu parfois dans cette liste la preuve de l'existence d'une ligue rivale de la ligue albaine contrôlée par Rome, placée sous le patronage de Tusculum et Aricie, et dirigée par un dictateur. Mais la citation de Priscien (qu'il emprunte à Flavius Caper) est tronquée, car elle s'arrête sur Ardeatis, qui est le terme qui intéresse le grammairien; la liste tronquée fournie par Caton correspond donc aux 30 (ou 29) cités latines révoltées contre Rome ${ }^{89}$. Cette consécration peut être datée des environs de 500, puisque Caton mentionne les cités de Cora et Pometia avant qu'elles ne tombent aux mains des Volsques ${ }^{90}$.

Nous voyons donc que dès la fin du $\mathrm{VI}^{\mathrm{e}}$ s., les «Ardéates Rutules» sont intégrés à la structure militaire et religieuse que nous définissons habituellement comme «ligue latine» et que les auteurs latins appellent nomen Latinum. En 498, au moment où la ligue latine entre en conflit avec Rome, les Ardéates apparaissent encore parmi les rangs des Latins (DH., V, 61, 3) et l'on doit donc considérer qu'à l'issue du conflit, Ardée devient à ce titre un des contractants du foedus Cassianum, qui réorganise l'alliance en mettant sur un pied d'égalité les Romains d'un côté et l'ensemble des Latins de l'autre (Cic., Balb., 23, 53; Liv., II, 33; DH., 21, 2) ${ }^{91}$.

${ }^{88}$ Trad. CUF : «Le lucus de Diane fut consacré dans le bois d'Aricie par Egerius Baebius de Tusculum, dictateur des Latins. Ces peuples réunis : de Tusculum, d'Aricie, de Lanuvium, de Laurentum, de Cora, de Tibur, de Pométia, les Rutules d'Ardée.» Il nous semble préférable toutefois de conserver à la $2^{\text {e }}$ phrase une traduction plus littérale : «Les peuples réunis : le (peuple) Tusculan, l'Aricin, le Lanuvinate, le Laurente, le Coran, le Tiburtin, le Pométian, l'Ardéate Rutule».

${ }^{89}$ Cf. C. Ampolo, art. cit. n. 10; J. Heurgon, Rome et la Méditerranée occidentale jusqu'aux guerres puniques, Paris, 1993, 3e éd. mise à jour, p. 263.

${ }^{90}$ Nous pouvons même proposer la date de 501, si l'on suppose que la création de la dictature à Rome cette année-là (Liv., II, 18) est une réaction à la nomination chez les Latins d'un dictateur, qui serait Egerius Baebius de Tusculum.

${ }^{91}$ Cf. A. Bernardi, Nomen Latinum, Pavie, 1973; C. Ampolo, Roma arcaica ed $i$ Latini nel $V$ secolo, dans Crises et transformation des sociétés de l'Italie antique au $V^{e}$ siècle av. J.-C. Actes de la table ronde organisée par l'École française de Rome et 
Cette alliance romano-latine est centrée sur le culte de Jupiter Latiaris sur le Monte Cavo et nous avons plusieurs témoignages de la participation d'Ardée aux féries latines, et donc de son appartenance à la ligue. Ainsi, l'inscription $C I L, \mathrm{I}^{2}, 39$, signalée plus haut, atteste la fréquentation du sanctuaire par les Ardéates, tandis que Tite-Live nous apprend qu'en 199, un décret des pontifes oblige à recommencer les féries latines après une plainte des légats d'Ardée de ne pas avoir reçu les viandes du sacrifice sur le mont Albain (Liv., XXXII, 1, 9).

\section{Ardée alliée de Rome puis colonie latine}

Nous n'avons pas de notices précises concernant Ardée dans le récit annalistique pour la première moitié $d u V^{e}$ s., mais à partir du milieu du siècle, les interventions romaines dans les affaires d'Ardée se font plus nombreuses ${ }^{92}$. En 445, en effet, les cités d'Ardée et d'Aricie s'affrontent à propos d'un territoire contesté, avant d'appeler les Romains comme arbitres (Liv., III, 71-72). Aux comices tributes, P. Scaptius rappelle que le territoire contesté appartenait aux fines Coriolanorum et revenait donc, par droit de conquête, aux Romains ${ }^{93}$. Cette contestation nous fait entrer de plain-pied dans le problème de l'organisation de la ligue latine. Malgré les sources annalistiques romaines, qui tendent à présenter les membres de la ligue comme les sujets de Rome, la situation était beaucoup plus équilibrée, avec un commandement alterné et un partage équitable du butin et des territoires conquis. C'est dans le contexte de ces partages que naît la contestation, à propos du territoire de Corioli, qui avait été détruite par les Volsques de Coriolan en 489 (Liv., II, 39; DH., VIII, 19, 4). Contre l'avis des

l'Unité de recherches étrusco-italiques associée au CNRS (UA 1132). Rome 19-21 novembre 1987, Rome, 1990 (Collection de l'École française de Rome, 137), p. 117-133.

${ }_{92}$ Cette période correspond à la longue série de guerres entre Rome et les Volsques et ces combats se déroulent probablement en partie sur le territoire d'Ardée. Les prospections menées sur le territoire témoignent en effet d'une chute importante du nombre de présences archéologiques correspondant à tout le $\mathrm{V}^{\mathrm{e}} \mathrm{s}$., alors que les attestations croissent à nouveau au $\mathrm{IV}^{\mathrm{e}} \mathrm{s}$. Cf. L. Crescenzi et E. Tortorici, art. cit. n. 78 , p. 348 .

${ }^{93} \mathrm{M}$. Torelli (Lavinio e Roma. Riti iniziatici e matrimonio tra archeologia e storia, Rome, 1984, p. 218-219) considère cet épisode comme une invention de l'annalistique récente destinée à illustrer la démagogie des tribuns de la plèbe; il s'appuie notamment sur le fait que le nom Scaptius est peu connu par ailleurs. Néanmoins, cet épisode s'insère bien dans le climat de tensions patricio-plébéiennes du milieu du $\mathrm{V}^{\mathrm{e}}$ s. Cf. F. Zevi, Il mito di Enea nella documentazione archeologica : nuove considerazioni, dans L'epos greco in Occidente. Atti del diciannovesimo convegno di studi sulla Magna Grecia. Taranto, 7-12 ottobre 1979, Tarente, 1989, p. 259. 
patriciens, les comices tributes romains décident que le territoire contesté appartient en réalité aux Romains (DH., XI, 52, 2-3). Les patriciens romains sont opposés à une telle décision et nous voyons alors se mettre en place une solidarité durable entre les patriciens de Rome et les élites d'Ardée, tandis que la composante plébéienne ardéate regarde plutôt du côté des Volsques ${ }^{94}$. Cependant, devant l'injustice évidente d'un tel arbitrage, le populus Ardeatium rompt avec Rome (Liv., IV, 1, 4; DH., XI, 54) : en 444, des délégués d'Ardée viennent à Rome pour déclarer que si on leur rendait le territoire, elle respecterait le foedus et l'amicitia. Le Sénat répond qu'il ne peut pas casser un jugement du peuple et il demande la confiance des Ardéates, qui se retirent. Peu après - sans que l'on comprenne bien à quelles conditions - le foedus avec Ardée est renouvelé (Liv., IV, 7; DH., XI, 62, 4) et Tite-Live s'en sert de base pour affirmer qu'il y eu bien cette année là deux consuls, qui ne figurent pas dans les listes ${ }^{95}$ : le nom de ces consuls apparaîtrait, selon Licinius Macer dans le foedus Ardeatinum conservé dans les libri lintei du temple de Junon Moneta ${ }^{96}$.

Après ce premier arbitrage, les relations entre les patriciens de Rome et d'Ardée se font plus étroites. L'année suivante, des envoyés d'Ardée viennent, au nom du foedus, demander l'aide romaine, alors qu'ils font face à une révolte de la plèbe (Liv., IV, 9). Le conflit a débuté à cause d'une jeune plébéienne que veulent épouser un plébéien et un nobilis. Le magistratus d'Ardée tranche en faveur du noble mais les tuteurs rassemblent une bande et enlèvent la jeune fille ${ }^{97}$. S'ensuivent des affrontements entre

${ }^{94}$ Cf. D. Briquel, art. cit. n. 75, p. 183.

${ }_{95}$ Pour cette année 444, Tite-Live mentionne d'abord des tribuns militaires à pouvoir consulaire (A. Sempronius Atratinus, L. Atilius, T. Cloelius), puis des consuls (L. Papirius Mugillanus et L. Sempronius Atratinus). Il semble y avoir une contradiction entre deux sources qu'il utilise (Licinius Macer lui fournissant le nom des consuls). Denys d'Halicarnasse, de son côté, ne mentionne que les tribuns militaires (XI, 61, 3).

${ }^{96}$ Cette mention d'un foedus Ardeatinum pose problème, dans la mesure où Ardée, en tant que membre de la ligue latine, a souscrit au foedus Cassianum. Il faut alors peut-être considérer que chaque cité latine adhérait pour son propre compte, et non collectivement, au traité. Cette idée est renforcée par le fait qu'à propos des Herniques, Denys précise qu'en 486, ils adhèrent à l'alliance romano-latine en souscrivant un foedus qui reprend les mêmes conditions que le foedus Cassianum, mais qui n'est pas le foedus Cassianum lui-même (DH., VIII, 69, 2).

${ }^{97}$ L'historicité de cet épisode a été fortement critiquée. Pour R. M. Ogilvie (The maid of Ardea, dans Latomus, XXI, 1972, p. 477-483), il ne sert qu'à expliquer un point de droit romain et est inséré artificiellement dans le récit annalistique. En effet, il illustre un litige possible après la promulgation de la lex Canuleia, qui autorise le conubium entre patriciens et plébéiens : une jeune fille sui iuris peut-elle se ma- 
nobles et plébéiens, qui font appel aux Volsques pour s'emparer d'Ardée (Liv., IV, 9-10). Les Volsques, conduits par l'èque Cluilius ${ }^{98}$ mettent le siège devant les murs d'Ardée. Le consul M. Geganius se porte contre eux et fait construire pendant la nuit un contre-retranchement pour prendre les Volsques à revers. Les Volsques ne peuvent plus alors se ravitailler en blé et l'imperator Volscus demande à voir le consul, qui refuse de traiter. S'ensuit une courte bataille, les Volsques déposent les armes et livrent leur imperator; ils passent sous le joug (et sont massacrés plus tard par les Tusculans) (Liv., IV, 10). En 442, le Sénat vote l'envoi d'une colonie à Ardée contre les Volsques, en prévoyant d'y enrôler plus de colons rutules que de Romains ${ }^{99}$. C'est la dernière mention des Rutuli en tant que tels dans le récit annalistique, Tite-Live n'utilisant plus par la suite que l'ethnique Ardeates. Tite-Live précise que les colons reçoivent des terres situées sur les territoires concernés par la sentence de 444, ce qui ne lèse pas les Ardéates, et que les triumvirs chargés de conduire la colonie sont Ag. Menenius, T. Cloelius Siculus ${ }^{100}$ et M. Aebutius Huelua. Plus que d'une "colonie», il s'agit ici de l'envoi d'une garnison de Romains et de Latins, chargés de renforcer la ville d'Ardée contre les Volsques et d'autre part de soutenir le patriciat de la ville en butte à l'hostilité des plébéiens ${ }^{101}$.

rier sans l'assentiment de son tuteur? En général, on considère que le mariage ne doit pas léser les agnati et par conséquent, l'avis du tuteur n'est nécessaire que pour les formes de mariage qui imposent le passage dans la manus du mari; dans le cas de l'usus, les biens de la mariée demeurent dans la famille d'origine et l'autorisation n'est pas nécessaire. Même si le caractère étiologique de ce récit est patent, il se comprend bien dans le contexte de tensions patricio-plébéiennes qui touchent toutes les cités du Latium et d'Étrurie à l'époque. Cf. l'histoire parallèle de Virginie à Rome (Liv., III, 44-48) ou d'Arruns de Clusium et son pupille Lucumon (Liv., V, 33; DH., XIII, 10-12; Plut., Cam., 17, 1-9; cf. M. Sordi, La leggenda di Arrunte chiusino e la prima invasione gallica in Italia, dans RSA, VI-VII, 1976-1977, p. 111-117).

${ }^{98}$ A. De Luigi a bien remarqué que le prénom de ce chef volsque, Aequus, laisse supposer qu'il s'agit en réalité d'un imperator èque, placé à la tête des troupes èques et volsques coalisées. Un autre chef èque de la famille des Cloelii, Gracchus Cloelius, l'ennemi de Cincinnatus, est mentionné dans les sources (Liv., III, 25-29). Cf. A. De Luigi, L'immagine degli Equi nelle fonti letterarie, dans SE, LXIX, 2003, p. 145-179.

${ }_{99}$ Diodore se limite à noter l'envoi de colons, qui se partagent le territoire (DS, XII, 34. 5).

${ }^{100}$ Ce dernier porte le même gentilice que l'imperator des Volsques mentionné un peu plus haut.

${ }^{101}$ Sur les mécanismes de la colonisation archaïque, cf. J. Bayet, Tite-Live et la précolonisation romaine, dans $R P h, 64,1938$, p. 97-119 = Mélanges de littérature latine, Rome, 1967, p. 351-375 et G. Bandelli, Colonie e municipi dall'età monarchica alle guerre sannitiche, dans Eutopia, IV, 2, 1995, p. 143-197. Sur la colonisation et les distributions de terres replacées dans le cadre des tensions entre patriciens et plé- 
À partir de la déduction de la colonie latine d'Ardée, nous constatons deux phénomènes : d'une part, les relations d'hospitium priuatum entre les grandes familles d'Ardée et de Rome se renforcent; d'autre part, l'ethnique Rutuli disparaît du récit annalistique, alors qu'est apparu, depuis une quarantaine d'année, dans l'onomastique romaine le cognomen Rutulus ${ }^{102}$. C'est en outre peu après la fondation de la colonie que les Marcii, gens plébéienne qui porte le cognomen Rutulus, apparaissent dans les Fastes ${ }^{103}$, avec M'. Marcius, édile de la plèbe en 442. Plusieurs familles romaines portent le cognomen Rutilus, que l'on trouve noté, dans certains manuscrits de Tite-Live comme Rutulus. Il s'agit des patriciens Verginii, Nautii, Cornelii et des plébéiens Marcii. En outre, il existe une gens Rutilia, qui est documentée à Rome dès le $\mathrm{II}^{\mathrm{e}} \mathrm{s}$. av. J.-C., si l'on ne tient pas compte du Sp. Rutilius Crassus, tribun militaire à pouvoir consulaire en 417, dont l'existence est contestée, ainsi qu'à Préneste à la même époque. Ce gentilice renvoie au prénom étrusque rutile ${ }^{104}$, connu en latin sous la forme $R u$ tila $^{105}$. Le cognomen Rutilus / Rutulus renvoie peut-être à une origine rutule des gentes en question ou à un lien particulier avec Ardée ${ }^{106}$. Les Verginii sont une des plus anciennes familles du patriciat romain et les Nautii font partie des familles qui revendiquent une origine troyenne. Cependant, P.-C. Ranouil considérait, sur la base des hypothèses de W. Schulze qu'il s'agissait de deux familles d'origine étrusque, intégrées au patriciat romain ${ }^{107}$. Les Nautii, comme de nombreuses gentes romaines, faisaient re-

béiens, cf. M. R. Torelli, Il problema storico della più antica colonizzazione latina, dans QAEI, II, 3, 1979, p. 193-196.

${ }^{102}$ Cf. T. R. S. Broughton, M. L. Patterson, The magistrates of the Roman Republic. I. 509 B.C.-100 B.C., New York, 1951.

${ }^{103}$ Les liens avec le roi Ancus Marcius et avec le patricien Cn. Marcius Coriolanus ne sont pas assurés. Cf. F. Münzer, s.u. Marcius, dans RE, XIV, 2, 1930, col. 1535 $s q$. Virgile (En., VI, $810 s q$.) suggère subtilement ces liens, en évoquant le roi Ancus «trop sensible à la faveur populaire», en des termes qui évoquent un tribun de la plèbe.

${ }^{104}$ Le prénom Rutile apparaît à Tarquinia sur un vase de la $2^{\mathrm{e}}$ moitié du VII ${ }^{\mathrm{e}} \mathrm{s}$. (ET Ta 6.1), pour désigner un individu d'origine grecque dont le gentilice n'est que la transcription du nom individuel grec, Rutile Hipucrates. Cf. M. Torelli, Storia degli Etruschi, Rome-Bari, 1981, p. 132. Sur cette même base est formé le gentilice rutlni, connu par deux inscriptions plus récentes de Volterra (ET Vt 1.148 et 1.149).

${ }^{105}$ Cf. A. Franchi De Bellis, I cippi prenestini, Urbino, 1997, p. 176.

${ }^{106}$ Cf. C. Ampolo, I gruppi etnici in Roma arcaica : posizione del problema e fonti, dans Gli Etruschi e Roma. Incontro di studio in onore di Massimo Pallottino. Roma, 11-13 dicembre 1979, Rome, 1981, p. 58.

${ }^{107}$ Schulze rapproche ainsi les Verginii du gentilice étrusque vercna. Cf. H. Gundel, s.u. Verginius, dans RE, VIII, 2, 1958, col. 1507 sq. 
monter leurs origines jusqu'aux compagnons d'Énée, en particulier à Nautes (Virg., En., V, $704 s q$. . $^{108}$, qui reçut le Palladium de Diomède, ce qui explique que les Nautii étaient chargés du culte de Minerve (Serv., II, 166; V, 704; DH., VI, 69, 1). Cette famille disparaît des Fastes consulaires après 287, ce qui permet de supposer que certaines de ces traditions familiales «troyennes» sont d'élaboration ancienne, contemporaine des ultimes mises en forme de la légende d'Énée dans le Latium ${ }^{109}$. Certaines familles, comme les Caecilii, qui dans un premier temps se réclamaient de Caeculus, fondateur de Préneste, finissent par se réclamer, dans un second temps, de Caecas, compagnon d'Énée. Il n'y a donc pas d'objection à ce que des Nautii «rutules», originaires d'Ardée, en viennent à se présenter comme des «troyens». Le cognomen Rutilus / Rutulus trahit peut-être l'origine ardéate de certaines gentes romaines et l'anecdote de la vierge d'Ardée met en avant l'importance des relations d'inter-mariage entre Rome et la cité des Rutules.

Les liens d'hospitium priuatum entre les nobles romains et ardéates apparaissent aussi à l'occasion de l'exil de Camille. En 390, accusé de fraude dans le partage du butin, le vainqueur de Véies trouve en effet refuge à Ardée (Liv., V, 32; 43-44; 51; DH., XIII, 5; Val.Max., IV, 1, 2; Plut., Cam., 23, 2-7; DC., XXXVIII, 26; App., II, 8, 2; BC, II, 8, 50). À l'annonce de l'arrivée des Gaulois à Rome, Camille prend la parole devant la contio de l'armée des Ardéates, ses «nouveaux concitoyens» (Liv., V, 44 : noui ...ciues mei). Camille prend la tête de l'armée ardéate contre les Gaulois et c'est vraisemblablement à la tête de ces troupes rutules ou plutôt d'une armée commune de la ligue, qu'il intercepte les Gaulois qui pillent le territoire latin (Liv., V, 45; Plut., Cam., 23, 6-7). De leur côté les Cérites combattent un autre de ces groupes gaulois dispersés (Strab., V, 2, 3) ${ }^{110}$. Après ces victoires initiales, Camille est nommé dictateur, mais il conserve les troupes ardéates, tandis que l'armée de Véies est placée sous le commandement du magister equitum L. Valerius (Liv., V, 48).

${ }^{108}$ Cf. F. Münzer, s.u. Nautius, dans RE, XVI, 2, 1935, col. 2049 sq.

${ }^{109}$ Cf. T. P. Wiseman, Legendary genealogies in late-republican Rome, dans $G \& R$, XXI, 2, 1974, p. 153-164.

${ }^{110}$ Strabon suit une tradition plus digne de foi, selon laquelle le butin fait par les Gaulois à Rome a été récupéré par les Cérites. Il s'oppose ainsi à la vulgate livienne qui veut que Camille ait interrompu le paiement de la rançon et vaincu les Gaulois sur la route de Gabies (Liv., V, 49; Plut., Cam., 29, 5-6). Sur la présence de petits groupes celtiques mobiles et bien au fait des usages diplomatiques en Italie centrale dans la première moitié du IV $\mathrm{IV}^{\mathrm{e}}$., cf. S. Bourdin, I Galli a Chiusi : riflessioni sulle modalità migratorie e sull'attività diplomatica dei Celti in Italia, dans Actes du colloque Celticità di confine?, Udine ottobre 2002, s. p. 
Ardée, colonie latine, demeure durant toute la première moitié du $\mathrm{IV}^{\mathrm{e}}$ s. le rempart des Latins face aux Volsques et Tite-Live signale, pour 340 par exemple, les dévastations opérées par les Volsques sur les territoires d'Ostie, Ardée et Solonium (Liv., VIII, 12). La ville n'est pas mentionnée durant la guerre latine de 340-338 et l'on ne sait rien de précis sur sa condition après $338^{111}$. Par la suite, ce sont les offensives samnites qui parviennent jusqu'au territoire d'Ardée et l'on date traditionnellement de ce moment le début du déclin de la ville ${ }^{112}$, même si la documentation archéologique amène à nuancer quelque peu les sources littéraires ${ }^{113}$. Dans le contexte des guerres contre les Volsques et les Samnites, le vieux système de fortifications est restauré, avec la construction d'un mur en opus quadratum qui entoure l'acropole et la Civitavecchia, dont on voit encore des portions au nord de la ville actuelle ${ }^{114}$. L'agger de Civitavecchia est doté d'une porte, flanquée de deux tours carrées et d'un pont qui enjambe le fossé. Cette nouvelle enceinte laisse en dehors le plateau de Casalazzara, qui ne semble plus désormais être occupé par l'habitat. Cette contraction de l'habitat se déduit aussi de la présence de tombes à chambre des $\mathrm{V}^{\mathrm{e}}-\mathrm{IV}^{\mathrm{e}} \mathrm{s}$., fouillées par des clandestins à la localité Vignacce, à l'intérieur de l'en-

${ }^{111}$ On suppose qu'elle perd alors son autonomie, comme les autres cités latines. Cf. Enea nel Lazio... cit. n. 78, p. 12. La ville demeure une colonie latine (Liv., XXVIII, 9) et ne devient pas municipe romain avant la guerre sociale.

${ }^{112}$ Cf. A. Boëthius, Le devastazioni sannitiche nell'Ardeatinum e Laurentinum, dans C. Galassi Paluzzi (dir.), Atti del V Congresso nazionale di studi romani, II, Rome, 1940, p. 231-238, qui a mis justement ce passage en relation avec les guerres du IV e s. et non avec l'offensive samnite de 82 av. J.-C., comme on l'a parfois proposé (Cf. A. Nibby, op. cit. n. 46, p. 203 et 230).

${ }^{113} \mathrm{On}$ assiste à un imposant programme de restauration de la décoration des temples entre la fin du IV et le début du III ${ }^{\mathrm{e}} \mathrm{s}$., avec des décorations portant des couples de palmettes en diagonale séparées par des $\mathrm{S}$, d'autres ornées de lys et des antéfixes à têtes de satyres et ménades (probablement alternées avec des représentations archaïques de la potnia theron). Ce cycle de restaurations et substitutions se poursuit au cours du $\mathrm{III}^{\mathrm{e}}$ s.; la dernière phase de restauration, avec des plaques comparables aux précédentes, se situe au Ir s. av. J.-C. Cf. G. Manca Di Morres, art. cit. n. 69, p. 313-314. On note aussi la présence d'un nymphée des $\mathrm{III}^{\mathrm{e}}-\mathrm{II}^{\mathrm{e}} \mathrm{s}$. à la localité Campetto. Au I ${ }^{\text {er }}$ s. av. J.-C. enfin, on assiste à une reprise de l'activité édilitaire, avec la construction de la basilique (vers 100-80), l'aménagement du forum, la réfection de la décoration des deux temples, de plusieurs maisons de l'acropole etc. Plusieurs concentrations de matériel attestent la survie de l'habitat d'Ardée jusqu'au $\mathrm{V}^{\mathrm{e}} \mathrm{s}$. ap. J.-C. au moins et de nombreuses inscriptions témoignent de la fréquentation des sanctuaires. Cf. C. Morselli, E. Tortorici, op. cit. n. 51, p. 38 sq.

${ }^{114}$ Cf. C. Morselli et E. Tortorici, op. cit. n. 51, p. 32 sq. Ce mur est bien préservé, tandis que le bastion qui lui est adossé est un ajout d'époque byzantine, construit avec des blocs récupérés sur l'enceinte antérieure. 
ceinte ${ }^{115}$, tandis que d'autres tombes, plus tardives, sont connues au delà de l'agger de Casalazzara.

Lors de la deuxième guerre punique, en 209, Ardée fait partie des colonies qui ne peuvent remplir leurs obligations militaires envers Rome, en raison du dépeuplement qui les frappe (Liv., XXVII, 9, 7; XXIX, 15, 5). Par la suite, la ville n'est plus évoquée qu'au travers des uillae ou des propriétés que possèdent les riches Romains sur son territoire, comme Lucilius (Sen., Ep., 105, 1) ou Columelle (III, 9, 2), pour la décoration de ses temples (Pline, XXXV, 17 et 115) ou pour ses sources sulfureuses (Vitr., VIII, 3, 2). Comme le note ironiquement Juvénal, le territoire des Rutules et de Turnus n'est plus que le lieu où l'on parque les éléphants réservés aux jeux publics (XII, 103 sq.).

\section{LA RÉINVENTION DU PASSÉ ARDÉATE}

Le passé le plus ancien d'Ardée, comme celui des principales villes du Latium, a fait l'objet d'une réécriture qui s'est produite en divers moments et dans des contextes différents. La fondation de la ville a ainsi fait l'objet d'une tentative d'insertion dans l'épos grec, tandis que les Rutules recevaient une place de choix, en tant qu'ennemis principaux des Troyens, dans la tradition sur Énée en Italie. Nous tenterons ici de démêler l'écheveau de ces traditions et de leurs différents contextes d'apparition.

\section{L'insertion d'Ardée dans l'épos}

Denys d'Halicarnasse nous rapporte une tradition, qu'il attribue à Xénagoras, au sujet de la fondation d'Ardée (DH., I, 72, 4; Stéph. Byz., s.u.

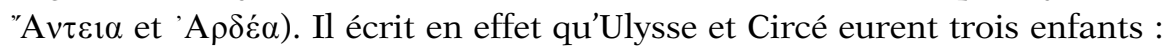

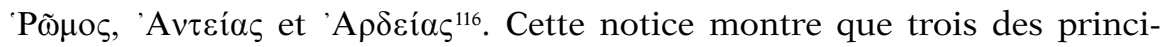
pales villes du Latium archaïque (Rome, Antium et Ardée) étaient rattachées par le jeu des origines gentium au monde grec, par le truchement de

${ }^{115}$ Cf. C. Morselli et E. Tortorici, op. cit. n. 51, p. 110-111. Le même phénomène est connu, à défaut d'être bien compris, à Satricum à la même époque. Cf. M. Gnade, Satricum II. The southwest necropolis of Satricum. Excavations 1981-1986, Amsterdam, 1992.

${ }^{116}$ Denys (I, 72) connaît plusieurs traditions qui font intervenir un Romos comme fondateur de Rome : selon Céphalon de Gergis, Romos serait le fils d'Énée et le père d'Ascagne, Euryléon, Romulos et Romos; selon Callias, le fils de Romè et Latinus; pour les «Romains», le fils d'Énée et le frère de Romulus et d'Ascagne (DH., I, $73,2)$, voire le fondateur de Capoue, d' 'A $\gamma \chi i ́ \sigma \eta$, d'Aïveı sur le Janicule et de Rome. 
trois héros fondateurs éponymes ${ }^{117}$. Il s'agit donc ici d'une tradition qui ne fait pas intervenir Énée et les Troyens dans le peuplement de l'Italie et que l'on considère habituellement comme concurrente. En effet, on attribuait à Ulysse, Diomède et Anténor, diverses fondations. Diomède avait laissé des traces sur toute la côte adriatique (Strab., V, 1, 9), avec la fondation d'Argyrippe, la «nouvelle Argos» (Strab., VI, 3, 9), de Bénévent (Solin., II, 13), de Sipontum (ibid.), de Spina (Plin., III, 120) et d'Adria (Stéph. Byz., s.u.

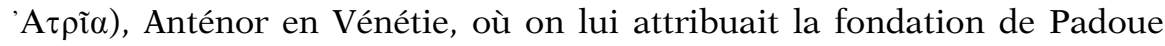
(Liv., I, 1; Solin., II, 13) et Ulysse sur la côte du Latium. Même si l'on discute encore du poids de l'expérience coloniale dans l'élaboration du corpus homérique, il ne fait pas de doute, au vu de documents comme la «coupe de Nestor» de Pithécusses par exemple, que des récits appartenant au cycle de la guerre de Troie et des nostoi étaient déjà bien connus des colons eubéens de Pithécusses. De là, ces thèmes sont passés précocement à la Campanie étrusquisée. Ces contacts culturels débouchent rapidement sur l'intégration des Étrusques à l'épos grec : Hésiode écrit en effet que d'Ulysse descendent Agrios et Latinos qui régnèrent sur les Tyrsénoi (v. 1011-1018) ${ }^{118}$ et dans le second quart du $\mathrm{VII}^{\mathrm{e}}$ s., le peintre Aristonothos représente l'aveuglement de Polyphème sur son célèbre cratère. Dans une première phase donc, le personnage d'Ulysse est proposé comme médiateur entre le monde grec et le monde étrusco-italique, et nous retrouvons des traces de ces anciennes traditions aussi bien en Étrurie ${ }^{119}$ qu'à Rome et à Ardée ${ }^{120}$.

Ces trois villes n'étaient pas les seules à se réclamer d'Ulysse : selon certaines traditions, Télégonos, fondateur de Tusculum, était fils d'Ulysse et de Circé (DH., IV , 45, 1). La fondation de Préneste était attribuée à ce même Télégonos (ps-Plut., Par.Min.., 41 b = Mor. $316 \mathrm{a}-\mathrm{b}$ ), à Caeculus, fils de Vulcain (Cat., Or., II, 29 Chassignet ap. Schol. Veron. ad Verg. Aen., VII, 681; Solin., II, 13; Serv., VII, 678), voire à Praenestos, fils de Latinus et

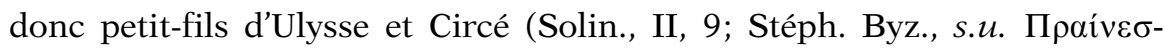

${ }^{117}$ Sur le mécanisme des origines gentium, cf. E. J. Bickerman, Origines gentium, dans $C P$, XLVII, 1952, p. 65-81.

${ }^{118}$ Ce passage est certainement une interpolation, mais celle-ci est tout de même ancienne, probablement du VI ${ }^{\text {e }}$ s. Cf. A. Alföldi, op. cit. n. 13, p. 238-239; D. Musti, art. cit. n. 23 , p. $30-31$

${ }^{119}$ Cf. par exemple Théopompe, FGrHist 115 F 354 ap. Schol. ad Lyc. Alex., v. 806 et Lyc., v. 795-807, à propos du tombeau d'Ulysse à Cortone. Cf. D. Briquel, Le tradizioni sulle origini di Perugia nel quadro dell'Etruria nord-orientale, dans Annali della Fondazione per il Museo "Claudio Faina», IX, 2002, p. 9-20.

${ }^{120} \mathrm{Cf}$. I. Malkin, I ritorni di Odisseo. Colonizzazione e identità etnica nella Grecia antica, Rome, 2004, p. 189 sq. 
$\tau \circ)^{121}$. Plutarque $($ Rom., 2, 1) signale également une version qui attribue la fondation de Rome à un Romanos, fils d'Ulysse et de Circé. Pour chaque ville importante du Latium - Lanuuium, Tibur, Lauinium - nous retrouvons le même phénomène. Certaines de ces reconstructions artificielles réutilisent des motifs ou des figures qui appartiennent au plus vieux fond mythologique latin, comme Cacus ou Caeculus ${ }^{122}$.

Il existe en outre un second motif qui est cette fois-ci particulier à Ardée : celui de la fondation par Danaé, mère de Persée (Virg., En., VII, 409 sq.; Plin., III, 56-57; Solin., II, 5; Serv., En., VII, 372). Servius est le plus disert : Danaé, après avoir été séduite par Zeus, fut enfermée dans un coffre avec son fils Persée et jetée à la mer par son père Acrisius, roi des Argiens. Recueillie par un pêcheur, elle est amenée devant le roi Pilumnus, qu'elle épouse. La famille de Turnus tiendrait d'elle son origine ${ }^{123}$. Virgile modifie légèrement la légende en affirmant que Danaé était accompagnée de colons argiens, envoyés par son père Acrisius (En., VII, 411 sq.). Ce récit, qui est aussi artificiel que celui de la légende d'Énée en Italie ${ }^{124}$, constitue un motif parallèle : la légende troyenne, dans la version qui nous est parvenue, est le récit qui rattache Lauinium, Rome et les Latins au monde grec; la légende de Danaé fait de même pour Ardée et les Rutules ${ }^{125}$. Cette généalogie grecque est ensuite ré-élaborée en y intégrant des personnages appartenant au fond mythologique local (Daunus, Venilia, Turnus) ${ }^{126}$. Ces deux traditions, qui attribuent la fondation d'Ardée à des descendants d'Ulysse ou de Danaé, ma-

${ }^{121}$ Cf. J. N. Bremmer et N. M. Horsfall, Roman myth and mythography, Londres, 1987, p. $47 s q$.

${ }^{122}$ Cf. J. N. Bremmer et N. M. Horsfall, op. cit. n. 121, p. 1 sq.; A. Carandini, op. cit. n. 35.

${ }^{123}$ Cf. H. W. Stoll, s.u. Danae, dans W. H. Roscher, Ausführliches Lexikon der griechischen und römischen Mythologie, I, Leipzig, 1884-1886.

${ }^{124}$ Ce récit n'est en effet jamais qu'une dérivation du mythe principal qui voit Danaé et Persée aborder sur l'île de Sériphos et être recueillis par le pêcheur Dictys, frère du roi Polydectès (Simonide ap., DH., Comp., VI, 26, 15; Ath., IX, 396 e).

${ }^{125}$ La structure même du récit est parallèle : Danaé parvient en Italie, alors qu'elle a déjà un fils, et y épouse le roi Pilumnus, dont elle a un autre fils, Daunus, qui règne sur les Rutules. Énée, lui, arrive en Italie avec son fils Ascagne, épouse Lavinie, fille du roi Latinus, dont il a un autre fils, Silvius, qui règne sur les Albains (OGR, XVI-XVII).

${ }^{126} \mathrm{Cf}$. A. Montenegro Duque, op. cit. n. 34. On retrouve le même phénomène à Lauinium, où la divinité Sol Indiges, honorée depuis la plus haute antiquité dans un sanctuaire au bord du Numicus, est identifiée dans un second temps à Énée. Cf. F. Castagnoli, I luoghi connessi con l'arrivo di Enea nel Lazio (Troia, Sol Indiges, Numicus), dans ArchClass, XIX, 1967, p. 235-247. Nous retrouvons ici le mélange entre mythes indigènes et mythes secondaires (cf. J. N. Bremmer et N. M. Horsfall, op. cit. n. 121, p. 1). 
nifestent chacune de son côté la volonté de rattacher la ville à l'épos grec. Si l'on suit I. Malkin, on peut considérer que la tradition sur Ulysse est d'élaboration antérieure (VIII ${ }^{\mathrm{e}} \mathrm{s}$.?), tandis que la légende de Danaé est probablement plus récente, sans que l'on puisse préciser davantage ${ }^{127}$.

On retrouve le motif d'une origine argienne pour d'autres centres du Latium : Tibur, fondé par Catillus ou Tiburnus (Virg., En., VII, 670 sq.; Hor., C., II, 6, 5-6), Cori, fondé par Coras (Serv., VII, 670-672). Le rite des argei à Rome était expliqué par la venue d'Argiens dans la suite d'Hercule (Varr., L., V, 45). De même, Faléries était considéré comme une fondation de l'argien Halesus (Cat., II, 18 Chassignet ap. Plin., III, 51; Ov., F., IV, 72 73; Solin., II, 7) ${ }^{128}$ et Denys rappelle que la forme des boucliers des gens de Faléries et Fescennium est argienne, de même que le temple d'Héra de Faléries, construit sur le modèle de celui d'Argos (DH., I, 21, 1-3). Le culte d'Héra Argienne rayonnait depuis le sanctuaire de l'embouchure du Sele (Strab., VI, 1, 1) et l'on en a rapproché notamment le culte de Junon Sospita à Lanuuium. On peut alors supposer pour ces traditions argiennes, une diffusion à partir de Poseidonia, colonie de Sybaris, dont le rôle dans la diffusion parallèle de l'arcadisme à Rome et ailleurs en Italie ${ }^{129}$, avec Stésichore notamment, a bien été mis en évidence par J. Bayet ${ }^{130}$. Cette légende ar-

${ }^{127}$ On pourrait supposer, à titre d'hypothèse, que cette tradition est apparue sous la plume d'Hellanicos de Lesbos, auteur par ailleurs d'une Chronique des prêtresses d'Argos. Denys d'Halicarnasse (DH., I, 72, 1) ne l'appelle d'ailleurs que «l'auteur de l'histoire des prêtresses d'Argos». Cf. G. Dury-Moyaers, Énée et Lavinium. À propos des découvertes archéologiques récentes, Bruxelles, 1981 (Latomus, 174), p. 53.

${ }^{128}$ Cf. G. Camporeale, L'ethnos dei Falisci secondo gli scrittori antichi, dans Miscellanea etrusca e italica in onore di Massimo Pallottino, 1, ArchClass, 43, Rome, 1991, p. 209-221; D. Briquel, Haleso, eroe campano (Virgilio, Eneide 7, 723-730) e i Falisci, coloni calcidesi (Giustino 20, 1, 13), dans L. Braccesi (dir.), Hesperìa, 4. Studi sulla grecità di Occidente, Rome, 1994, p. 83-94. G. Camporeale montre bien que Faléries se définit tour à tour comme étrusque, en raison de ses liens politiques et militaires avec la dodécapole, argienne ou chalcidienne (Just., XX, 2), sicule / pélasge / romaine. Il pense que la légende d'Halesus est une élaboration locale, falisque, datant du milieu du IVe s. (ou avant) reprise par les auteurs grecs.

${ }^{129}$ Sur la base du témoignage de Denys (I, 21, 1-3) sur les Falisques, D. Briquel a proposé aussi de lier l'identité argienne à la tradition pélasge (cf. D. Briquel, op. cit. n. 32, p. 327-352). Chez Nonnos (Dion., XLVII, 534; 555; 716), Héra est ainsi quali-

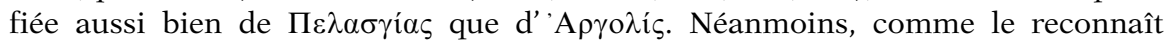
D. Briquel, cette relation ne vaut probablement que pour Denys et rien n'indique que les autres cultes d'Héra, celui du Sele en particulier, aient revendiqué cette tradition pélasgique.

${ }^{130}$ Cf. J. Bayet, Les origines de l'arcadisme romain, dans MEFR, XXXVIII, 1920, p. 63-143 = Idéologie et plastique, Rome, 1974 (Collection de l'École française de Rome 21), p. 43-123. 
gienne a pu être bien accueillie à Ardée, dans la perspective de se démarquer des villes revendiquant des origines troyennes, Rome et la voisine Lauinium.

\section{La tradition troyenne pré-virgilienne}

Le thème de la constitution et de la réception de la légende troyenne en Italie a été amplement débattu depuis un demi-siècle ${ }^{131}$. Plutôt que d'une tradition, il est d'ailleurs plus juste d'évoquer plusieurs filons contradictoires. Ainsi, on peut distinguer une tradition troyenne romaine, qui fait d'Énée le fondateur de Rome (Sall., Cat., 6) ${ }^{132}$, d'une tradition lavinate. La tradition sur la fondation de Rome par Énée se heurte vite au fort enracinement de la figure de Romulus, héros fondateur et c'est alors par l'intermédiaire d'Albe et de la généalogie de ses rois, que Rome se rattache à l'épopée troyenne ${ }^{133}$. Les notices qui nous sont parvenues sur le plus ancien passé d'Ardée et des Rutules appartiennent à l'épopée troyenne et nous devons donc tenter de distinguer, dans un premier temps, la tradition prévirgilienne de la tradition virgilienne.

Dans l'Iliade, Homère laissait en suspens le sort d'Énée après la guerre de Troie, en précisant seulement, dans la prophétie de Poséidon, qu'il rè-

${ }^{131}$ Sur la constitution progressive de la légende troyenne en Italie, la bibliographie est immense. On se reportera particulièrement à : A. Alföldi, op. cit. n. 13, p. 236 sq.; J. Perret, Rome et les Troyens, dans REL, 49, 1971, p. 39-52; F. Castagnoli, art. cit. n. 126; Enea nel Lazio... cit. n. 78; T. J. Cornell, Aeneas' arrival in Italy, dans LCM, 2, 1977, p. 77-83; J. Poucet, Le Latium protohistorique et archä̈que à la lumière des découvertes archéologiques récentes (deuxième partie), dans AC, XLVIII, 1979, p. 177-220; F. Zevi, Note sulla leggenda di Enea in Italia, dans Gli Etruschi e Roma. Atti dell'incontro di studio in onore di Massimo Pallottino. Roma, 11-13 dicembre 1979, Rome, 1981, p. 145-158; G. Dury-Moyaers, op. cit. n. 127; F. Castagnoli, La leggenda di Enea nel Lazio, dans Atti del Convegno mondiale scientifico di studi su Virgilio. Mantova, Roma, Napoli 19-24 settembre 1981, II, Milan, 1984, p. 283-303; G. D'Anna, L'Eneide e la tradizione preesistente, ibid., p. 207-219; J. N. Bremmer et N. M. Horsfall, op. cit. n. 121; A. Momigliano, Saggi di storia della religione romana. Studi e lezioni 1983-1986, Brescia, 1988; G. D’Anna, Il mito di Enea nella documentazione letteraria, dans L'epos greco in Occidente. Atti del diciannovesimo convegno di studi sulla Magna Grecia. Taranto, 7-12 ottobre 1979, Tarente, 1989, p. 231-244; F. Zevi, art. cit. n. 93 , p. 247-290.

${ }^{132}$ Cette tradition semble remonter à Ateius Philologus, maître de Salluste (Suét., De gramm., 10; Serv., I, 273) et à travers lui à «Hypérochos» (Fest., p., 328 L.). Cf. G. D'Anna, art. cit. n. 129, p. 233 sq.

${ }^{133}$ Ce schéma se retrouverait chez Dioclès de Péparéthos et de là chez Fabius Pictor. Il s'agissait en particulier de combler l'écart entre les deux dates fournies par Timée pour la chute de Troie (1184) et la fondation de Rome (814). Cf. D’Anna, art. cit. n. 131, p. 239 sq. 
gnerait sur les Troyens (XX, 302-308) ${ }^{134}$. Sur la base de la Tabula Iliaca, on pense en général que Stésichore est le premier à évoquer les aventures d'Énée en Occident ${ }^{135}$, alors qu'on connaît d'autres versions selon lesquelles les Énéades auraient régné en Troade (Strab., XIII, 52-53) ou qui attribuent à Énée la fondation de plusieurs cités en Méditerranée orientale ${ }^{136}$. C'est avec Hellanicos de Lesbos (FGrH I, 4 F 84 ap. DH., I, 72, 1) et Damaste de Sigée (ap. DH., I, 72, 2) que l'on a les premières mentions sûres de l'arrivée d'Énée en Italie et Timée fournit à la fin du $\mathrm{IV}^{\mathrm{e}} \mathrm{s}$. un récit plus détaillé, en se rendant personnellement à Lauinium pour y recueillir les développements locaux de la légende (FGrH 566 F 59, ap. DH., I, 67, 3-4). À partir de Timée (et Lycophron qui s'en inspire), les notices sur la fondation de Lauinium par Énée tendent à supplanter la tradition sur la fondation de Rome même. La légende d'Énée fondateur de Rome semble donc être une invention grecque $\mathrm{du} \mathrm{V}^{\mathrm{e}} \mathrm{s}$., alors que celle de la fondation de Lauinium est connue dès la fin du $\mathrm{IV}^{\mathrm{e}} \mathrm{s}$. et remonte peut-être au $\mathrm{V}^{\mathrm{e}}$, voire au VI ${ }^{\mathrm{e}} \mathrm{s} .{ }^{137}$. L'iconographie atteste en outre la diffusion précoce de la légende d'Énée en Étrurie, même si l'idée d'un culte d'Énée chez les Étrusques et d'une antériorité étrusque dans la réception de la légende est désormais abandonnée ${ }^{138}$.

${ }^{134}$ Cf. F. Castagnoli, La leggenda di Enea nel Lazio, dans Enea nel Lazio... cit. n. 78, p. 3 sq.

${ }^{135}$ Les scènes de ce relief du I ${ }^{\text {er }}$ S. ap. J.-C., provenant de Boville et représentant la destruction de Troie, s'inspirent de la légende. Malgré l'inscription qui dit que le

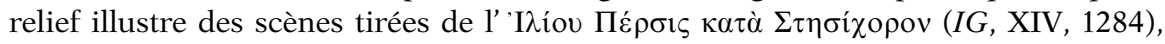
tout ne remonte probablement pas à Stésichore. Cf. F. Castagnoli, art. cit. n. 78, p. 3 et G. Dury-Moyaers, op. cit. n. 127, p. 48-49.

${ }^{136}$ Une des plus anciennes récupérations du mythe d'Énée est documentée par des monnaies de la cité d'Aineia en Chalcidique de la fin du VI ${ }^{\mathrm{e}} \mathrm{s}$. Cf. G. DuryMoyaers, op. cit. n. 127, p. 166.

${ }^{137}$ Pour G. Dury-Moyaers, op. cit. n. 127, p. 64, le texte d'Hésiode évoquerait à travers Latinos et Agrios les deux centres de Lauinium et Albe. La tradition troyenne de Lauinium serait donc antérieure à celle de Rome, qui ne s'affirmerait que très provisoirement au $\mathrm{V}^{\mathrm{e}} \mathrm{s}$., avec Hellanicos, avant d'être précocement abandonnée. Cette légende troyenne de Lauinium serait reprise dans un second moment par Timée. Une interprétation différente a été proposée par C. Cogrossi (Atena Iliaca e il culto degli eroi. L'heròon di Enea a Lavinio e Latino figlio di Odisseo, dans M. Sordi (dir.), Politica e religione nel primo scontro tra Roma e l'Oriente, Milan, 1982 [CISA, 8], p. 79-98) et A. Grandazzi (Le roi Latinus : analyse d'une figure légendaire, dans CRAI, 1988, p. 481-495) : le personnage divinisé au $\mathrm{VI}^{\mathrm{e}} \mathrm{s}$. à Lauinium, quand on transforme en hérôon le tumulus du VII ${ }^{\mathrm{e}}$ s., est probablement Latinus, assimilable à Sol Indiges. Ce n'est qu'après la prise de contrôle du Latium par Rome en 338 que le personnage d'Énée recouvrirait celui de Latinus-Indiges, au moment où l'hérôon est restructuré.

${ }^{138}$ Cf. G. Dury-Moyaers, op. cit. n. 127; F. Zevi, art. cit. n. 93. 
Cette tradition pré-virgilienne se retrouve en premier lieu dans des œuvres que nous ne possédons qu'à l'état de fragments : les Origines de Caton (fr. I, 9 a-12 Chassignet), les ouvrages de plusieurs annalistes romains ${ }^{139}$, les Annales d'Ennius et les Punica de Naevius. Ces fragments nous sont connus notamment à travers les ouvrages d'antiquaires plus tardifs, comme le grammairien Festus, le commentateur Servius ou l'Origo gentis Romanae. Enfin, cette tradition pré-virgilienne est suivie par Tite-Live et Denys d'Halicarnasse. Naevius (fr. 3 Morel) fait arriver les Troyens chez les Latins, de même qu'Ennius (fr. 19 Vahlen ap. Varr., L., VII, 28), qui défend une chronologie courte et fait d'Énée le grand père de Romulus et Rémus (fr. 25 Morel ap. Serv.Dan., I, 273). On pense habituellement que Fabius Pictor est l'inventeur de la dynastie albaine, destinée à combler l'intervalle entre la destruction de Troie et la fondation de Rome, mais rien ne le dit explicitement $^{140}$. Qu'on l'attribue à Dioclès de Péparéthos (Plut., Rom., 3, 1-2) ou à Fabius lui-même, c'est dans le courant du $\mathrm{III}^{\mathrm{e}}$ s. qu'est attestée pour la première fois la dynastie albaine.

Avec les fragments des Origines de Caton, il est possible de reconstituer pour la première fois un discours articulé. Pour Caton, le Latium est peuplé, au moment de l'arrivée d'Énée, par les Aborigènes, qui deviennent les Latins quand ils fusionnent après les Troyens (I, 6 Chassignet ap. Serv., En., I, 6). Énée reçoit de Latinus un territoire de 2.700 jugères, situé entre Laurentum (= Lauinium) et le camp troyen (I, 8 Chassignet ap. Serv., En., XI, 316); il épouse également Lavinie (I, 11 Chassignet ap. Serv., En., VI, 760). Turnus, à qui était promise Lavinie, prend les armes contre Latinus et Énée, avec l'appui de son allié Mézence qui offre son aide aux Rutules à la condition que les prémices lui soient offerts au lieu d'être sacrifiés aux dieux (I, 12 Chassignet ap. Macr., Sat., III, 5, 10; Plut., Mor., 275 e $)^{141}$. Turnus est vaincu et meurt dans la bataille, tandis qu'Énée

${ }^{139}$ Avec les auteurs suivants, donnés d'après l'édition de M. Chassignet $(C U F)$ : Fabius Pictor : fr. 1, 5a et b, 7 a; Postumius Albinus : fr. 2-3; Acilius : fr. 2; Cassius Hemina : fr. 8; Fabius Maximus : fr. 1; Calpurnius Pison : fr. 3-4; Sempronius Tuditanus : fr. 2; Cn. Gellius : fr. 9; Lutatius Catulus : fr. 2-6; Sisenna : fr. 1-3. En revanche, aucun fragment conservé des Annales Maximi ne se réfère à la légende troyenne. Le récit semble plutôt commencer avec la généalogie des rois d'Albe (cf. fr. 4 Chassignet ap. OGR, XVII, 5; fr. 5 Chassignet ap. OGR, XVIII, 3).

${ }^{140}$ Ainsi, dans l'inscription de Taormine (frg. 1 Chassignet), on apprend simplement qu'il évoquait le passage d'Hercule en Italie, l'arrivée de Lanoios, Énée et Ascagne et «bien plus tard» la fondation de Rome par Romulus. Le fragment qui mentionne le prodige de la truie et la fondation d'Albe est une citation de troisième main, assez peu fiable (fr.5 a Chassignet ap. DS., VII, 5, 4-5 ap. Sync., p. 229 Mossh.).

${ }^{141}$ Denys, qui suit Varron, évoque aussi les exigences de Mézence, mais il écrit 
disparaît (I, 11 Chassignet). C'est Ascagne qui met fin à la guerre, en tuant Mézence au cours d'un combat singulier et par la suite, il fonde Albe (I, 11 Chassignet).

Le récit de Caton, tel qu'on peut le reconstituer, n'est pas dépourvu d'incohérences $^{142}$. Ainsi, dans les fr. 9 a Chassignet (ap. Serv., En., I, 267) et 10 Chassignet (ap. Serv., En., IV, 620), Latinus meurt lors d'un premier accrochage entre les Troyens en quête de terres et les Laurentes, tandis que dans le fr. 11 Chassignet (ap. Serv., En., VI, 760), il succombe lors de la guerre contre Turnus. On a parfois supposé que Caton exposait des traditions divergentes, mais il faut plutôt reconnaître, avec J.-C. Richard, que les fragments 9 et 10 ne sont pas catoniens ${ }^{143}$. De la même manière, alors que Laurentum-Lauinium semble préexister à l'arrivée d'Énée (I, 8 Chassignet), qui n'aurait fondé que Troia (I, 7 Chassignet ap. Serv., En., I, 5), un autre fragment évoque les trente années qui séparent la fondation d'Albe de celle de Lauinium, qu'il faut donc attribuer alors à Énée (I, 14 b Chassignet ap. OGR, XII, 5). Une partie de la confusion vient du fait que les citations, chez Servius en particulier, sont mises en contexte avec des éléments empruntés à diverses traditions et qui ne remontent pas tous à Caton ${ }^{144}$. Nous retiendrons avant tout que chez Caton, Turnus est roi des Rutules (Ardée n’apparaît pas dans les fragments) et allié au tyran étrusque Mézence. Le nom même de Turnus-Tyrrhénos semble se justifier par cette alliance avec

simplement que le tyran réclame aux seuls Latins leur production de vin. Cet événement n'est pas lié aux Rutules et se situe après la mort d'Énée, lors de la guerre entre Ascagne et Mézence (I, 65, 2). Pline l'Ancien (XIV, 88), en revanche, mentionne le vin mais en rapport avec les Rutules et il se réfère explicitement à Varron. Selon M. Gras (Trafics tyrrhéniens archä̈ques, Rome, 1985 [Bibliothèque des Écoles françaises d'Athènes et de Rome, 258], p. 425 sq.), le personnage de Mézence s'inspirerait de la figure réelle d'un tyran de Caere. D. Briquel (La fabrication d'un tyran: Mézence chez Virgile, dans $B A G B, 1995$, p. 173-185) a bien montré que Virgile a profondément modifié ce personnage, dont on connaît un parent, Laucie Mezentie, par une inscription du début du VII ${ }^{\mathrm{e}} \mathrm{s}$. (cf. D. Briquel, A propos d'une inscription redécouverte au Louvre : remarques sur la tradition relative à Mézence, dans $R E L, 67,1989$, p. 78-92). Sur les Vinalia, cf. R. Schilling, La religion romaine de Vénus depuis les origines jusqu'au temps d'Auguste, Rome, 1954 (Bibliothèque des Écoles françaises d'Athènes et de Rome, 178), p. $91 s q$.

${ }^{142}$ Cf. R. Crahay et J. Hubaux, art. cit. n. 33, p. 160-162.

${ }^{143}$ Cf. J.-C. Richard, Ennemis ou alliés? Les Troyens et les Aborigènes dans les Origines de Caton, dans H. Zehnacker et G. Hentz (dir.), Hommages à Robert Schilling, Paris, 1983, p. 403-412.

${ }^{144}$ Le passage de Caton sur les trente années est probablement contaminé par un passage de Varron, qui serait le premier à introduire ce motif. Cf. G. DuryMoyaers, op. cit. n. 127, p. 88. 
le monde étrusque ${ }^{145}$. Caton intègre probablement à la saga troyenne des personnages et des thèmes autonomes, appartenant aux anciennes traditions latines, comme Mézence ${ }^{146}$. À partir des Origines, les principaux éléments de la légende sont déjà en place. Dans cette légende troyenne centrée sur Lauinium, les Rutules d'Ardée apparaissent déjà comme les ennemis implacables d'Énée. Il faut alors supposer que cette tradition s'est formée dans un contexte de reflux de l'influence étrusque dans le Latium - comme l'indique l'hostilité envers Mézence ${ }^{147}$ - et d'hostilité entre Lauinium et sa proche voisine Ardée.

Cette version catonienne se retrouve à peu de variantes près chez les annalistes qui le suivent, comme Cassius Hemina, et en fin de chaîne chez Tite-Live, qui apporte peu d'éléments nouveaux (I, 1-2) ${ }^{148}$. Tite-Live évacue en effet assez vite la légende troyenne dont il ne brosse que les grands traits : il indique que dans un premier moment, Énée s'oppose aux Aborigènes de Latinus, avant de conclure un foedus avec lui. Après la fondation de Lauinium, les Aborigines Troianique entrent en guerre contre Turnus, roi des Rutules et Latinus meurt lors d'un premier combat. Turnus se tourne alors vers Mézence, rex Etruscorum, tandis qu'Énée donne le nom de Latini à la population née de la fusion des Troyens et des Aborigènes. Tite-Live évoque ensuite la disparition d'Énée, sans même mentionner le sort de Turnus. Comme chez Caton, nous constatons qu'il n'y a pas de lien explicite entre les Rutules et Ardée ${ }^{149}$.

${ }^{145}$ Cf. G. Dury-Moyaers, op. cit. n. 127, p. 85. Pour la justification de l'alliance Mézence-Turnus par l'influence étrusque dans le Latium archaïque, cf. E. Manni, Le tracce della conquista volsca del Lazio, dans Atheneum, XVII, 1939, p. 252 et D. Musti, Etruria e Lazio arcaico nella tradizione (Demarato, Tarquinio, Mezenzio), dans QAEI, 15, 1987, p. 151 sq.

${ }^{146}$ Cf. T. J. Cornell, art. cit. n. 131, p. 82; J. N. Bremmer et N. M. Horsfall, op. cit. n. 121, p. 8; D. Briquel, art. cit. n. 141.

${ }^{147}$ Ce n'est que dans l'Énéide que l'on retrouve une attitude étruscophile qui tend à distinguer Mézence du reste de l'Étrurie et à faire des Étrusques les alliés d'Énée. Cf. D. Musti, Tendenze nella storiografia romana e greca su Roma arcaica. Studi su Livio e Dionigi d'Alicarnasso, dans QUCC, 10, 1970, p. 30 sq. et D. Briquel, art. cit. n. 141.

${ }^{148}$ Cette version catonienne de la légende se retrouve chez Strabon $(\mathrm{V}, 3,2)$ et devait se trouver aussi chez Dion Cassius, si l'on en juge par le résumé de Zonaras (VII, 1) et une notice de Tzetzes (ad Lyc.Alex., v. 1232). On la trouve aussi chez Denys (I, 45, 1-2), qui commence par présenter de façon synthétique la vulgate, avant d'exposer systématiquement les variantes.

${ }^{149}$ Ce n'est qu'à l'occasion du siège de la ville par Tarquin le Superbe que TiteLive établit pour la première fois un lien net entre Ardée et les Rutules (I, 57). 
En revanche, la tradition est fortement développée par Varron, dont s'est inspiré Denys d'Halicarnasse (I, 53 sq.). On y trouve la prophétie de la truie au trente gorets. On y apprend également que Latinus était en guerre contre les Rutules au moment de l'arrivée d'Énée (DH., I, 57, 2), ce qui explique mieux l'entente entre Troyens et Aborigènes. Après le mariage d'Énée et Lavinie, qui scelle cette entente, on assiste à un nouveau soulèvement des Rutules, sous la conduite de Turnus (DH., I, 64, 2). Latinus et Turnus meurent dans un premier combat et Énée règne trois ans avant de disparaître à son tour lors d'un nouveau conflit contre les Étrusques et les Rutules coalisés. Après la mort d'Énée, survenue lors de cette deuxième guerre avec les Rutules (I, 64, 4), Denys raconte la guerre entre Ascagne et Mézence et n'évoque plus les Rutules (I, 65) ${ }^{150}$.

Dans cette version, on voit que Turnus n'est pas tenu comme responsable de l'alliance avec les Étrusques et encore une fois, on ne trouve pas de lien avec Ardée; Denys se contente de parler d'une $\pi$ ó $1 \varsigma$ des Rutules, sans la nommer (I, 59, 2) ${ }^{151}$. Il semble en effet que les Rutules aient un statut de population pré-urbaine, barbare, dans la tradition catonienne comme dans la version varronienne. Ce n'est que chez Virgile que les Rutules de Turnus sont liés clairement à Ardée. On peut donc supposer que les versions primitives de la légende mentionnaient les Rutules comme une population seminomade. Cette identité rutule étant revendiquée par la suite par la cité d'Ardée, comme on le voit chez Tite-Live à propos du siège de 510, Virgile remonte dans le temps le lien des Rutules avec Ardée et il introduit la ville d'Ardée elle-même dans la légende troyenne, qui ne connaissait auparavant que les Rutules.

\section{Les Rutules dans l'Énéide et au-delà}

Comme on l'a noté depuis longtemps, l'Énéide marque une rupture dans l'évolution de cette légende troyenne. Virgile utilise la tradition précédente et son œuvre témoigne d'une très grande connaissance du cadre ethnographique, géographique et mythologique de l'Italie ${ }^{152}$. On a aussi depuis longtemps souligné les modifications que Virgile fait subir à la lé-

${ }^{150}$ C'est cette version que suit l'auteur de l'OGR. On le voit notamment au fait que l'alliance entre les Rutules et les Étrusques est située après la mort de Turnus $(\mathrm{XIV}, 1)$ et que les Rutules ne sont plus mentionnés durant la guerre entre Ascagne et Mézence (XV, 1-4).

${ }^{151}$ Un peu plus loin $(I, 64,4)$, il parle de plusieurs $\pi$ ó $\lambda \varepsilon 1 \varsigma$ des Rutules, mais il ne s'agit que d'un artifice narratif.

${ }^{152}$ Cf. B. Rehm, op. cit. n. 39; F. Della Corte, op. cit. n. 38. 
gende, en déplaçant le cadre géographique de l'action vers l'embouchure du Tibre - au prix de quelques invraisemblances ${ }^{153}$ - et en élargissant le cadre ethnographique, à travers le jeu des alliances, aux dimensions de la péninsule ${ }^{154}$. En outre, la structure narrative elle-même est dictée par le désir d'égaler Homère, ce qui le conduit à construire le personnage de Turnus en s'inspirant tour à tour d'Achille et d'Hector ${ }^{155}$.

Virgile accorde une grande importance aux Rutules dans la mesure où il développe la figure de Turnus pour en faire la némésis d'Énée. Dès le premier livre, la prophétie annonce qu'Énée s'établira en Italie et qu'il subjuguera les Rutules (En., I, 261 sq.). Dans sa perspective pan-italienne, Virgile détaille également le parcours de la flotte troyenne avant d'arriver dans le Latium, en développant les épisodes campaniens : la consultation de la Sibylle de Cumes (III, 441 sq.; VI, 1 sq.), la descente dans l'Averne (VI, 236 sq.), la mort de Caieta à Gaète (VII, 1) etc., jusqu'à l'arrivée à l'embouchure du Tibre (VII, $30 \mathrm{sq}$.). Sur ce territoire et sur le peuple des Laurentes $^{156}$ règne Latinus, fils de Faunus et de la nymphe Marica (VII, $45 s q$.). Virgile est le premier à donner un cadre urbain à l'Italie de la légende, probablement pour imiter l'Iliade : il évoque ainsi l'urbs des Laurentes (VII, 171), dominée par le palais de Picus aux cent colonnes, les murs d'Ardée, capitale des Rutules (VII, 409; IX, 738) et l'urbs d'Évandre sur le Palatin (VIII, $95 s q$.).

Après un premier combat, provoqué par Allecto, les deux camp mettent sur pied des coalitions. La première liste concerne les alliés de Turnus (VII, 647 sq.) : l'étrusque Mézence et son fils Lausus d'Agylla, Aventinus fils d'Hercule, les argiens Tiburtus et Catillus de Tibur, Coras de Cori, Cae-

${ }^{153}$ Ainsi, le Numicus, que l'on identifie actuellement avec le fosso di Pratica, est singulièrement proche du Tibre (En., VII, 147 sq.).

${ }^{154}$ Cf. J. Carcopino, op. cit. n. 11; A. Montenegro Duque, op. cit. n. 34; F. Della Corte, op. cit. n. 38; F. Castagnoli, dans Enea nel Lazio, op. cit. n. 78, p. 5.

${ }^{155}$ La bataille finale entre Énée et Turnus (Virg., En., XII, 697-952) a ainsi été mise en parallèle avec le combat d'Achille et d'Hector (Hom., Il., XXII, 136-137) par D. West (The deaths of Hector and Turnus, dans G\&R, XXI, 2, 1974, p. 21-31). On y retrouve la même alternance de phases de fuite et de combat, la même discussion entre les dieux avant ou pendant l'affrontement. La principale différence réside dans le ton même de l'auteur : Homère évoque le combat avec des accents réalistes, tandis que chez Virgile, tout est excès et surnaturel.

${ }^{156}$ Virgile n'emploie qu'une fois, en effet, le terme d'Aborigenes (VII, 181), avec un sens très général. Il désigne toujours comme Laurentes le peuple de Latinus. Cf. A. Bernardi, s.u. Aborigini (Aborigines), dans Enciclopedia Virgiliana, I, Rome, 1984, p. 6-7 et G. Maddoli, s.u. Latini (Latini), dans Enciclopedia Virgiliana, III, Rome, 1987, p. 129-131. 
culus de Préneste avec des troupes prénestines et herniques, Messapus et ses contingents falisques, Clausus et ses Sabins, Halesus et ses soldats aurunces, sidicins et osques, Oebalus avec les peuples sarrastes et campaniens, Ufens de Nersae chez les Èques, Umbro et les Marses, et enfin Virbius. Virgile distingue en outre des contingents qui sont placés sous le commandement direct de Turnus (VII, 793 sq.) : la jeunesse argienne (les Ardéates), les troupes aurunces, rutules, sicanes, les Sacrani, les Labicans, Camille et ses guerriers volsques. Le domaine de Turnus est étendu depuis le Tibre jusqu'au Circeo et à Terracine.

Pendant ce temps, Énée se rend auprès d'Évandre pour lui proposer une alliance (VIII, 51 sq.). Ce dernier lui apprend que l'Étrurie s'est révoltée contre Mézence et que Tarchon attend Énée pour lui confier le commandement (VIII, 496 sq.). Ce motif est une invention de Virgile, car dans la tradition précédente, l'Étrurie est toujours rangée derrière Mézence ${ }^{157}$. Énée prend le commandement de la flotte étrusque (X, 148 sq.), composée de Massicus et des troupes de Clusium et Cosa, Abas avec les gens de Populonia et Elbe, Asilas et les Pisans, Astyr et les gens de Caere, Pyrgi et Grauisca, Cupavo et Cinyra et leurs guerriers ligures, Aulestès à la tête des Mantouans. Un peu plus loin, on trouve Acron, venu de Cortone (X, 719 sq.).

La reconstitution de la légende par Virgile manifeste donc la volonté d'exalter l'unité de la péninsule, à travers la participation de l'Italie, et en particulier de l'Étrurie, qui est intégrée dans le poème comme une réalité essentielle $^{158}$ et la principale contributrice à la grandeur de Rome ${ }^{159}$. Virgile fait montre d'une bonne connaissance antiquaire, tant au niveau des références historiques et géographiques, que dans la reconstitution onomastique. Les noms des personnages considérés comme des Rutules par Virgile rappellent des toponymes ou des ethniques qui renvoient au monde étrusque, au Latium archaïque et à la Campanie, et manifestent bien cette volonté d'offrir à l'Italie une épopée nationale. Chaque population participe de la grandeur de l'Italie romaine. Les Rutules sont en partie l'instrument de cette unification, au même titre que les Aurunces ou les Laurentes.

La reconstitution proposée par Virgile a parfois été jugée sévèrement

${ }^{157}$ Cf. M. Pallottino, s.u. Etruschi (Etrusci, Tusci, Tyrrheni), dans Enciclopedia Virgiliana, II, Rome, 1985, p. 411-415. Chez Lycophron également, les Étrusques apparaissent comme les alliés d'Énée (v. 1239 sq.), par l'intermédiaire d'un personnage défini comme vóvos, que l'on identifie avec Ulysse.

${ }^{158}$ Cf. M. Pallottino, art. cit. n. 157. Sur l'intention virgilienne de valoriser l'Étrurie, cf. également G. Colonna, Cortona e la leggenda etrusca di Dardano, dans ArchClass, XXXII, 1982, p. 1-13 et D. Briquel, art. cit. n. 141, p. 179-181.

${ }^{159} \mathrm{Cf}$. M. Sordi, Virgilio e la storia romana del IV sec. a. C., dans Athenaeum, XLII, 1964, p. 99-100. 
en raison de son caractère artificiel ${ }^{160}$. Elle a dans une certaine mesure occulté les traditions précédentes et Ovide, par exemple, la suit sans hésiter, quand il évoque les deux coalitions antagonistes (M., XIV, 454 sq.) ou quand il utilise des noms donnés par Virgile, comme le rutule Ramnes ( $I b$., v. 631-632). À la suite de Virgile, Ovide établit un lien direct entre Ardée et les Rutules et il prolonge le poème inachevé en faisant suivre la mort de Turnus de la chute et de l'incendie de sa ville (M., XIV, 573). L'image virgilienne des Rutules s'impose donc et devient même un sujet d'ironie pour Juvénal, pour qui la rivalité entre Troyens et Rutules n'est plus qu'un thème littéraire, le symbole même de la préciosité antiquaire (I, 163 sq.; VII, 66 $s q$.). Contre toute vraisemblance, il parle de «montagnes rutules» (VI, 634 $s q$.) et raille la magna mens de Virgile, tout occupée de Rutules et sans souci du quotidien (VII, 66 sq.).

\section{Prétention hégémoniQue et iDentité ethniQue}

L'identité des Rutules, ancienne population du Latium, s'est donc maintenue depuis les temps les plus reculés jusqu'à l'époque d'Auguste. Son contenu a considérablement varié et Virgile propose le dernier état de cette recomposition. Pour quelles raisons et par quels moyens la cité latine d'Ardée a-t-elle conservé cette identité ethnique particulière, qui a été ensuite réélaborée par les poètes?

Plusieurs ethniques nous sont connus pour le Latium proto-historique. Les sources signalent la présence des Albenses ${ }^{161}$, des Latini, des Laurentes, des Rutuli, chacun ayant une localisation particulière ${ }^{162}$. On peut donc supposer qu'à cette époque, les différentes identités correspondent à des ensembles cohérents, qui se reconnaissent comme tels et se distinguent des autres au moyen de leur nom. Les Albenses correspondent aux communautés de villages des Monts Albains, tandis que, par opposition, les (Prisci) La-

${ }^{160} \mathrm{G}$. Dury-Moyaers note qu'il s'agit avant tout d'une construction savante (op. cit. n. 127, p. 33).

${ }^{161}$ C. Ampolo (L'organizzazione politica dei Latini ed il problema degli Albenses, dans A. Pasqualini [dir.], Alba Longa. Mito storia archeologia. Atti dell'Incontro di studio. Roma-Albano Laziale 27-29 gennaio 1994, Rome, 1996, p. 135-160) est le seul à considérer que les populi Albenses ne correspondent pas à une réalité historique. Pour le point de vue traditionnel sur les Albenses, cf. A. Bernardi, Dai populi Albenses ai Prisci Latini nel Lazio arcaico, dans Athenaeum, 42, 1964, p. 223-260.

${ }^{162}$ Les sources fournissent d'autres noms énigmatiques, comme les Rhèques

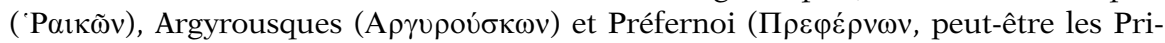
vernates?) cités par Strabon $(\mathrm{V}, 3,4)$. 
tini occupent la région basse, située entre le Tibre et l'Aniene ${ }^{163}$, zone que Cicéron appelle ager Latiniensis pour le distinguer de l'ager Latinus (Cic., Har., 10, 20), terme dont l'acception s'est étendue à son époque à l'ensemble de la région. Sur la côte, on trouve des groupes qui se définissent comme Laurentes, entre le Tibre et le Numicus, et plus au Sud, les Rutuli. Ces populations partagent la même culture matérielle et les ethnonymes traduisent simplement l'appartenance à des structures politico-sociales différentes. Par la suite, avec l'affirmation de l'organisation urbaine, les premiers synœcismes et l'émergence de la structure politique de la cité-État, ces identités survivent un certain temps. La notion d'Albenses s'efface à partir du moment où Rome affirme son autorité sur la ligue latine, avec la prétendue destruction d'Albe par Tullus Hostilius, puis à l'époque des rois étrusques qui réorganisent symboliquement le culte de Jupiter Latiaris sur le Mont Albain.

Rome s'impose donc aux Latini, en promouvant plusieurs sanctuaires pan-latins (le sanctuaire de Diane Aventine et celui de Jupiter Latiaris). Cependant, d'autres cités ont pu, à d'autres moments, chercher à rassembler une ligue autour d'elles, défendre d'autres identités ethniques pour se distinguer et proposer d'autres sanctuaires pan-latins. Ainsi, à la fin du VI ${ }^{\mathrm{e}}$ s., les principales cités des Latins, dont Aricie, Tusculum et Ardée, se regroupent autour du sanctuaire de Nemi, sur le territoire d'Aricie. C'est peut-être à ce moment qu'est réaffirmée la figure de Latinus, ancêtre des Latins ${ }^{164}$.

La survie des ethniques Laurentes et Rutuli peut s'expliquer de la même manière. En effet, cette identité ethnique est conservée par deux cités voisines, Lauinium et Ardée, qui possèdent de nombreux traits communs : la conservation anormale d'un ethnique double, la présence d'un Aphrodision sur leur territoire, la récupération de la légende troyenne. Ainsi, Pomponius Mela (II, 71) et Pline l'Ancien (III, 57) mentionnent la présence d'un Aphrodisium situé sur la côte entre Ardée et Antium. Pline précise que le sanctuaire n'existe plus à son époque, mais il existait encore,

${ }^{163}$ Quand Tite-Live évoque la guerre de Tarquin l'Ancien contre les Prisci Latini, il énumère des centres localisés au N.E. de Rome : Corniculum, Ficulea Vetus, Cameria, Crustumerium, Ameriola, Medullia, Nomentum (I, 38, 4). Leur appellation alternative de Casci Latini s'explique peut-être aussi par cette proximité avec la Sabine, puisque le mot cascus était considéré comme un emprunt au sabin (Varr., L., VII, 28). Cf. A. Bernardi, art. cit. n. 161, p. 251.

${ }^{164}$ A. Grandazzi (art. cit. n. 137) a mis en lumière une scholie d'un manuscrit de Cicéron (Comm. à Cicéron, Planc., 23, in Stangl, Ciceronis orationum scholiastae, 1912, p. 154) et un passage de Festus (p. 212, 15 L.) qui rappellent que Latinus est devenu Jupiter Latiaris après sa mort. La légende de Latinus est donc l'expression de l'identité communautaire. 
en revanche, à l'époque de la source de Strabon $(\mathrm{V}, 3,5)$, qui mentionne également la présence d'un autre Aphrodision, commun aux Latins (Kouvòv $\tau \tilde{\omega} v \Lambda \alpha \tau i ́ v \omega v)$, sur le territoire de Lauinium. Strabon précise en outre que ce sanctuaire est administré par les Ardéates. L'accord ne s'est pas encore fait à propos de ces notices. Certains ont songé à une confusion de Strabon et nié qu'il ait pu y avoir deux sanctuaires d'Aphrodite aussi proches ${ }^{165}$. Il semble plus raisonnable toutefois de conserver au texte de Strabon sa cohérence et d'accepter l'existence de deux sanctuaires dédiés à Aphrodite. La présence de sanctuaires côtiers, ainsi que le fait qu'ils soient mentionnés sous une forme grecque par les auteurs latins, permet d'affirmer leur rôle de sanctuaire emporique ${ }^{166}$. La localisation de ces sanctuaires n'est pas sûre. Certains ont songé au sanctuaire de la Madonella à Lauinium, où se trouvent les fameux 13 autels et l'hérôon dit d'Énée ${ }^{167}$, mais cette identification ne fait pas l'unanimité ${ }^{168}$. Récemment, en étudiant les archives de la collection Campana, G. Colonna a proposé, quant à lui, de localiser l'Aphrodision d'Ardée à la localité Banditella, où on connaît également plusieurs tombes à chambre ${ }^{169}$. Les décorations architectoniques les plus anciennes semblent indiquer une fondation vers le milieu du VI ${ }^{\mathrm{e}} \mathrm{s}$. Au-delà des problèmes de localisation et du fait que l'on comprend mal l'affirmation de Strabon sur le fait que le culte de Lauinium était placé sous la responsabilité d'Ardée ${ }^{170}$, nous retiendrons que ces deux villes possédaient chacune un sanctuaire d'Aphrodite "pan-latin» ${ }^{171}$, à vocation "fédérale». C'est peut-être d'ailleurs la rivalité entre les deux cités, manifestée à travers la concurrence pour le culte d'Aphrodite qui sert de substrat à la légende de l'opposition entre Énée, fondateur de Lauinium et Turnus, roi des Ru-

${ }^{165}$ Cf. A. Alföldi, op. cit. n. 13, p. 256.

${ }^{166}$ Cf. F. Zevi, art. cit. n. 131. p. 154-156; M. Torelli, op. cit. n. 93, p. 217.

${ }^{167}$ Cf. F. Castagnoli, op. cit. n. 126, p. 95; A. Dubourdieu, Le sanctuaire de Vénus à Lavinium, dans REL, LIX, 1981 (1982), p. 83-101; M. Torelli, op. cit. n. 93, p. 15 sq.

${ }^{168}$ Cf. F. Zevi, art. cit. n. 131, p. 147 sq., qui rejette à juste titre toute interprétation des autels comme un ensemble unitaire, qu'on l'interprète comme un sanctuaire "fédéral», une image des 12 mois de l'année etc., dans la mesure où la construction des autels s'est étalée sur plusieurs siècles et que jamais les 13 autels n'ont été tous ensembles en activité.

${ }^{169}$ Cf. G. Colonna, Gli scavi del 1852 ad Ardea e l'identificazione dell'Aphrodisium, dans ArchClass, XLVII, 1995, p. 1-67.

${ }^{170}$ Pour M. Torelli, Ardée, colonie latine, contrôlerait le culte pour le compte de Rome (op. cit. n. 93, p. 271 sq.). L'incertitude demeure mais étant donné que Lauinium est très fortement dépeuplée dès le $\mathrm{II}^{\mathrm{e}} \mathrm{s}$. av. J.-C., on peut supposer qu'Ardée a pris en charge les sacra.

${ }^{171}$ Pour reprendre une expression préconisée par F. Zevi, au lieu de «fédéral» qui prête à confusion (art. cit. n. 93, p. 277). 
tules $^{172}$. De même, cette guerre entre Énée et Turnus pour la possession du royaume de Latinus (puisque Lavinie est l'unique héritière) reflète peutêtre la rivalité des deux villes pour le contrôle du Latium ou pour l'hégémonie sur la ligue latine ou sur une ligue partielle ${ }^{173}$.

Cette revendication de l'hégémonie sur les Latins par Lauinium, au $\mathrm{VI}^{\mathrm{e}}$ s., apparaît avec la transformation du tumulus de la Madonella en hérôon pour le culte de Pater Indiges, identifié à Latinus dans un premier temps, puis, dans un second temps, à Énée ${ }^{174}$. Cette légende latino-troyenne lavinate relègue bien évidemment les voisins ardéates dans le camp des ennemis, guidés par Turnus le Rutule. Néanmoins, Ardée, de son côté, a élaboré sa propre légende troyenne. F. Zevi a en effet remarqué que chacun des deux sanctuaires d'Aphrodite correspond à un lieu de débarquement supposé des Troyens : ceux-ci seraient arrivés dans un lieu nommé Troia, sur le territoire des Laurentes, selon une tradition bien diffusée (Liv., I, 1; DH., I, 53) ${ }^{175}$. Ardée avait cependant développé une tradition concurrente, si l'on en croit la notice de Stéphane de Byzance qui dit que la ville d'Ardée portait plu-

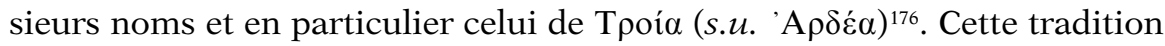
est en contradiction avec la revendication de l'identité rutule, mais les identités ethniques varient en fonction des intérêts diplomatiques. Ardée, port de Lanuuium, fondation de Lanoios, a pu se présenter à certains moment comme une ville troyenne et abandonner cette tradition par la suite pour revendiquer une identité rutule. Le même phénomène s'est produit à Rome, avec le développement au $\mathrm{V}^{\mathrm{e}} \mathrm{s}$. de la tradition faisant de la Ville une fondation d'Énée, avant que cette théorie, défendue par les familles patriciennes «troyennes» qui en tiraient leur légitimité augurale, ne soit abandonnée sous la pression plébéienne, si l'on suit l'interprétation de M. Torelli ${ }^{177}$.

Chaque cité importante du Latium assure ses prétentions hégémoniques en développant sa propre légende de fondation et des récits qui la rattachent au monde grec, en promouvant un sanctuaire commun au nomen etc. Les cités de l'intérieur, qui puisent davantage au vieux fond de traditions locales, se réfèrent plus volontiers à Diane, avec les sanctuaires «fédéraux» de l'Aventin pour Rome, de Nemi pour Aricie, de Corne pour Tusculum

${ }^{172}$ Cf. R. Crahay et J. Hubaux, art. cit. n. 33, p. 178.

${ }^{173}$ A. Bernardi (art. cit. n. 161, p. 245) y voit une rivalité plus ancienne et le signe d'une antique dépendance des Laurentes vis-à-vis des Rutules d'Ardée.

${ }^{174}$ Cf. Enea nel Lazio, op. cit. n. 78, p. 169 sq.

${ }^{175}$ Cf. F. Castagnoli, art. cit. n. 126.

${ }^{176}$ Cf. F. Zevi, art. cit. n. 131, p. 140. Cette notice remonte à Jean Charax (VI' ${ }^{\mathrm{e}} \mathrm{s}$

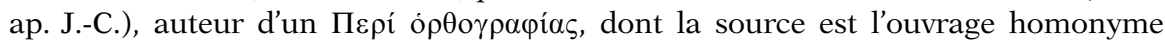
d'Hérodien ( $2^{\mathrm{e}}$ moitié du $\mathrm{II}^{\mathrm{e}}$ s. ap. J.-C.).

${ }^{177}$ Cf. M. Torelli, op. cit. n. 93, p. 285 sq. 
(Plin., XVI, 91, 242) ${ }^{178}$; les cités côtières affirment le caractère pan-latin de leurs cultes emporiques d'Aphrodite (Lauinium, Ardée) ${ }^{179}$. Lauinium défend ses prétentions hégémoniques en récupérant la figure de Latinus et en en faisant le roi des Laurentes ${ }^{180}$; le fait de se réclamer de l'éponyme des Latins n'est pas indifférent! Les deux villes se rattachent en outre à un ethnonyme, conservé depuis l'époque pré-urbaine, les Rutules à Ardée et les Laurentes à Lauinium $^{181}$. L'affirmation de ces identités est donc le reflet de tentatives d'hégémonie, d'équilibres socio-politiques momentanés, dont le détail ne nous est pas parvenu.

À cette ambition hégémonique d'Ardée sur une partie du Latium et à l'époque du rayonnement de son port de Castrum Inui à l'embouchure du Fosso dell'Incastro remonte probablement la légende qui relie aux Rutules la fondation de Sagonte. Les Sagontins revendiquaient en effet une double origine : on y trouvait des colons de Zacynthe et des Rutules d'Ardée (Liv., XXI, 7, 2; Sil., I, 283 sq. et 667 sq.). F. Coarelli est récemment revenu sur cette notice, qu'il interprète comme un signe de l'intensification des relations entre le Latium et l'Espagne au IV ${ }^{\mathrm{e}}$ s. et de l'établissement d'un foedus entre Rome et Sagonte dès cette époque ${ }^{182}$. Néanmoins, la mention dans ces notices de l'ethnique Rutuli renvoie à une époque où Ardée se réclame de cette identité ethnique. Il faudrait plutôt y voir un écho de la puissance maritime ardéate à la fin du VI ${ }^{\mathrm{e}}$ s. et des réseaux d'échanges établis avec l'Espagne ${ }^{183}$. Les pres-

${ }^{178}$ Cf. C. Ampolo, art. cit. n. 87.

${ }^{179}$ Le fait même que les auteurs latins désignent ces sanctuaires comme des Aphrodisia témoigne de leur importance pour les Grecs. De même, l'épiclèse Frutis que Strabon attribue à la Vénus de Lauinium est interprétée comme une déforma-

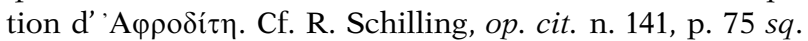

${ }^{180} \mathrm{Cf}$. A. Grandazzi, art. cit. n. 137, p. 491 sq. Énée se superpose à Latinus dans un deuxième temps et ils partagent les mêmes caractéristiques : tous deux combattent Mézence, sont rois des Latins, meurent au combat...

${ }^{181}$ C. Battisti (op. cit. n. 15, p. 147) considère que le nom des Laurentes dérive de la même racine que le lat. laurus et qui remonterait peut-être au méditerranéen *la$\mathrm{pa} /$ laba / lava, que l'on retrouverait dans Lauinium, Labicum.

${ }^{182}$ Cf. F. Coarelli, L'origine mitica di Sagunto e l'alleanza con Roma, dans V. Fromentin et S. Gotteland (dir.), Origines gentium, Bordeaux, 2001, p. 321-326.

${ }^{183} \mathrm{Cf}$. à ce propos les remarques faites par A. Barzanò (La questione dell'identità zacintio-ardeate dei Saguntini : invenzione erudita, falso diplomatico o realtà storica?, dans M. Sordi (dir.), Autocoscienza e rappresentazione dei popoli nell'antichità, Milan, 1992 [CISA, XVII], p. 135-143) : étant donné que les sources les plus anciennes (Hécatée cité par Stéphane de Byzance, le périple archaïque que suit l'Ora maritima d'Aviénus) ne connaissent pas Sagonte, on peut supposer que la ville s'est formée de l'agrégation au site indigène de K $\rho \alpha \beta \alpha \sigma i ́ \alpha$ de populations grecques de Zacynthe, au début du Ve s., selon un modèle qui rappelle celui d'Ampurias (Strab., III, 4, 8). Dans cet emporion de 
criptions du premier traité avec Carthage, qui interdisent la navigation audelà du "Beau promontoire», constituent peut-être la réaction de Carthage face aux incursions toujours plus nombreuses des navires latins ${ }^{184}$.

Il semble donc que, comme dans le cas de Lauinium, les différentes légendes sur les origines d'Ardée, celle qui en fait une fondation troyenne (Stéph. Byz., s.u.) et celle qui revendique l'identité rutule, se soient élaborées à une date assez haute, probablement dès le $\mathrm{VI}^{\mathrm{e}}$ s., au moment où Ardée, comme d'autres cités du Latium, rivalise avec Rome pour imposer son autorité à la ligue latine. On peut tenter de préciser davantage. L'héritage rutule d'Ardée est lié à l'image du roi Turnus; or, on ne peut que noter à ce propos, la confusion et le parallélisme entre les deux figures du roi Turnus et de Turnus Herdonius ${ }^{185}$. L'auteur de l'OGR confondait les deux personnages et les traits communs ne sont probablement pas fortuits. Turnus Herdonius avait tenté de s'opposer à la prise de contrôle de la ligue latine par Tarquin le Superbe (Liv., I, 49, 8-52,2; DH., IV, 45-48). Ce dernier le fit accuser de complot et Turnus fut noyé dans la fontaine Férentine ${ }^{186}$, donnant ainsi son nom au lacus Turni, que l'on identifie désormais avec le Laghetto de Castel Savelli ${ }^{187}$, près d'Aricie, situé à proximité du caput Ferentinae, qui n'est autre que l'émissaire du lac albain. Ce Turnus est originaire de Kopí $\lambda \lambda \eta$ selon Denys (IV, 45, 4), terme que l'on interprète comme Corioli, située entre Aricie et Ardée. Or, la figure de ce Turnus Herdonius est fortement contaminée par celle du roi Turnus : sa colère est motivée par le fait que Tarquin a accordé la main de sa fille à Octavius Mamilius (DH., IV, 47, 4), il meurt noyé, l'enjeu

Sagonte, on devait également rencontrer des Italiens et parmi eux les Rutules d'Ardée avaient une préséance telle qu'on les comptait parmi les «fondateurs» de Sagonte.

${ }^{184}$ Dès le $V^{e}$ s., une notice, un peu obscure il est vrai, fait état d'une tentative d'envoi d'une colonie romaine en Corse (Th., HP, V, 8, 2). Cf. M. Torelli, Colonizzazioni etrusche e latine di epoca arcaica : un esempio, dans Gli Etruschi e Roma. Incontro di studio in onore di Massimo Pallottino. Roma, 11-13 dicembre 1979, Rome, 1981, p. 71-82. Au même moment, Carthage tente de contrôler les initiatives étrusques vers les Colonnes d'Hercule, comme le rapporte Diodore (V, 20, 4; Mir.ausc., 84). Cf. Et. Colozier, Les Étrusques et Carthage, dans MEFR, LXV, 1953, p. 63-98.

${ }^{185}$ Pour le détail des parallèles entre les deux personnages, cf. R. Crahay et J. Hubaux, art. cit. n. 33.

${ }^{186}$ On a depuis longtemps remarqué le lien entre la noyade ou la disparition dans un fleuve et les antiques procédures de divinisation dans le Latium. Cf. A. Brelich, Tre variazioni romane sul tema delle origini, Rome, 1955, p. 86-87.

${ }^{187}$ Cf. C. Ampolo, Ricerche sulla lega latina, dans PP, XXXVI, 199, 1981, p. 219233; A. Grandazzi, Identification d'une déesse : Ferentina et la ligue latine archaïque, dans CRAI, 1996, 1, p. 273-294. 
est l'hégémonie sur les Latins etc. Cette assimilation des deux personnages amène à penser qu'Ardée, sur le territoire de laquelle Corioli est située ${ }^{188}$, revendique la direction de la ligue latine et développe en parallèle l'image du roi Turnus, probablement en des termes plus positifs que dans les versions lavinates qui nous sont parvenues.

C'est donc à l'époque des rois étrusques de Rome, dans le courant du VIe s., qu'il faut placer l'apogée d'Ardée et de ses aspirations au contrôle de la ligue latine. C'est à cette époque que sont élaborés les récits qui exaltent ses origines grecques (Danaé), troyennes et rutules. Les origines grecques facilitent les relations avec le monde hellénique. Les origines troyennes sont une claire réaction à l'élaboration parallèle de la légende par les concurrentes Rome et Lauinium, tandis que les origines rutules sont une revendication claire, à travers l'étiologie du lacus Turni et l'exaltation du roi Turnus, de l'hégémonie d'Ardée sur la ligue latine, ou sur une ligue plus réduite pour laquelle on exhume l'identité "rutule». Les prétentions d'Ardée entraînent d'ailleurs la guerre avec Tarquin le Superbe, qui met le siège devant la ville des Rutules en 510, pas tant pour piller ses richesses, que pour soumettre la rivale de Rome.

Les Rutules ont donc longtemps été considérés comme une population étrusque. Néanmoins, la documentation épigraphique et archéologique permet d'affirmer qu'il s'agit d'un peuple latin. Les sources littéraires ellesmêmes rappellent la participation des Ardéates à la dédicace du sanctuaire de Nemi, à la révolte des Latins contre Rome au début du $\mathrm{V}^{\mathrm{e}} \mathrm{s}$. et surtout aux sacrifices de Jupiter Latiaris, ce qui permet de les considérer, en tous points, comme des Latins. L'ethnonyme Rutuli est un héritage de l'époque protohistorique, quand coexistaient dans le Latium de nombreux noms de peuples, dont certains ont disparu au fur et à mesure que s'étendait le «nom latin » ${ }^{189}$, tandis que d'autres se sont maintenus, en étant utilisés comme ethniques civiques par des cités. Nous rencontrons alors une stratégie de distinction ethnique, une volonté de se démarquer, pour des raisons qui ne nous sont pas toujours claires, d'une autre identité, celle des Latins en l'occurrence ${ }^{190}$. L'identité ethnique, le fait de se reconnaître comme un groupe

${ }^{188} \mathrm{Cf}$. la controverse entre Aricie et Ardée pour la possession de l'ager Coriolanus. Cf. supra.

${ }^{189}$ Cette dénomination officielle de la ligue latine est d'ailleurs évocatrice. Sont Latins tous ceux que l'on appelle «Latins», qui portent le nom de «Latins».

${ }^{190}$ Cette volonté de se distinguer d'un groupe «externe» en se reconnaissant comme appartenant à un autre groupe est le fondement de l'identité ethnique. C'est ce processus que F. Barth qualifie de "frontière ethnique». Cf. F. Barth (dir.), Ethnic groups and boundaries. The social organization of culture difference, Oslo, 1969. 
(et d'exclure par là même comme «étrangers » d'autres éléments) est une notion transitoire et négociable; les peuples ne sont pas des entités immuables mais le produit de contingences historiques. Tout au long de l'histoire du Latium, la signification et l'extension des ethnonymes, voire leur pertinence, ont considérablement varié.

Ainsi, Ardée revendique tour à tour son identité grecque - argienne - ou se pose en concurrente de Lauinium comme lieu de débarquement alternatif des Troyens d'Énée. Dans cette perspective «troyenne», Ardée s'appuie sur le sanctuaire pan-latin d'Aphrodite situé sur son territoire, concurrent direct de l'Aphrodision de Lauinium. Dans le courant du VI ${ }^{\mathrm{e}}$ s., elle se réclame également de ses origines rutules. En effet, le vieil ethnonyme, dont l'extension précise nous échappe, est systématiquement accolé à l'ethnique civique, sans le remplacer tout à fait. À travers la geste de Turnus, qui est rattaché à une longue généalogie de divinités italiques (Pilumnus, Daunus, Juturne), les Ardéates mettent en valeur leur lointaine tradition indigène et cherchent à légitimer leurs revendications d'hégémonie sur la ligue latine. On conserve des traces de ces ambitions à travers l'épisode de Turnus Herdonius, le second Turnus, qui tente vainement de prendre le contrôle de l'alliance lors d'une réunion au caput Ferentinae. Quand Ardée passe sous le contrôle de Rome, avec l'envoi de colons en 442, l'identité rutule perd de sa pertinence; s'impose alors la version lavinate des aventures d'Énée, qui fait des Rutules les ennemis acharnés d'Énée et des Latins. Mais déjà, comme le disait bien Juvénal, les Rutules n'étaient plus que l'affaire des érudits et des poètes.

\section{Stéphane Bourdin}

